\title{
Pobreza e indigência no Brasil - algumas evidências empíricas com base na PNAD 2004
}

Sonia Rocha Economista, pesquisadora do Instituto de Estudos do Trabalho e Sociedade (IETS)

\section{Palauras-chave}

pobreza, renda, mercado de trabalho.

\section{Classificação JEL I32.}

Key words

poverty, income, labor market.

JEL Classification 132.

\section{Resumo}

Este artigo traz resultados empíricos relativos à incidência de pobreza e de indigência do ponto de vista da renda, baseados nos resultados da PNAD 2004. Trata especificamente das tendências de espacialização da pobreza, assim como dos eventos intervenientes recentes no que concerne ao funcionamento do mercado de trabalho e à formação da renda das famílias. O forte declínio da pobreza e da indigência entre 2003 e 2004, que foi o melhor resultado obtido desde o Plano Real, constitui o pano de fundo para a análise, embora os efeitos observados sejam diferenciados, mais favoráveis em áreas rurais e mais adversos na metrópole de São Paulo. O aumento da renda das famílias é devido principalmente à expansão da ocupação, já que o rendimento do trabalho manteve-se constante. No entanto, os indivíduos mais pobres se beneficiaram da redução do retorno à educação, do aumento real do salário mínimo e da ampliação da cobertura da rede de proteção social, que resultaram numa maior melhoria da renda na base da distribuição, permitindo também a queda da desigualdade.

\section{Abstract}

This article presents income-based indicators using the data from the 2004 Brazilian National Household Survey regarding poverty and indigence in 2004. It refers to spatial characteristics of poverty, as well as its relation with the functioning of the labor market and the way family income is formed. The relatively sharp reduction in poverty and indigence from 2003 to 2004, the best result obtained since the Real Plan was implemented, constitutes the background for the analysis, although the impact of this reduction is spatially differentiated, more favorable in rural areas and less so in the São Paulo metropolitan area. The increase in family income is mainly due to the vigorous expansion of occupation, as the average labor income remained unchanged. Nevertheless, poor individuals benefited from the reduction in the returns to schooling, from the real increase in the minimum wage and from the wider scope of the social security net, which resulted in a more vigorous income increase at the base of distribution, thus leading to a reduction in inequality. 


\section{1_Introdução}

Em comparação com outros países de nível de desenvolvimento semelhante, o Brasil apresenta uma vantagem importante quando se trata de estabelecer políticas voltadas para a redução da pobreza e da desigualdade: as informações estatísticas consistentes e comparáveis para um período longo, derivadas da Pesquisa Nacional por Amostra de Domicílios (PNAD/IBGE). O tamanho da amostra, que cobriu 140 mil domicílios em 2004, além da variedade de temas e a riqueza de detalhes investigados de forma permanente ou eventual, permitiram que se desenvolvesse no País uma sólida tradição de acompanhamento da evolução econômica e social, assim como de entendimento de relações de causalidade relevantes, no que concerne a comportamentos demográficos, econômicos e sociais. A PNAD 2004 inova em dois aspectos dignos de nota. Por um lado, torna-se verdadeiramente nacional, ao cobrir pela primeira vez a área rural da região Norte. Por outro, investiga no seu suplemento aspectos relativos à cobertura dos novos programas de transferência de renda focalizados nos mais pobres, que vem ganhando importância crescente desde a virada do milênio.
Este texto, que se baseia somente nos resultados do corpo principal da pesquisa, ${ }^{2}$ tem por objetivo analisar alguns resultados da PNAD 2004, no que diz respeito ao comportamento da pobreza e da indigência, principalmente a comparação com o que se verificou em 2003. Em alguns casos, apresenta-se uma série mais longa, de modo a colocar as evidências numa perspectiva realista, já que os dois anos - 2003 e 2004 - tiveram características opostas em termos de crescimento econômico, o que afeta diretamente os resultados sobre a evolução da renda das famílias e a incidência de pobreza e de indigência.

Pobreza e indigência serão tratados aqui exclusivamente sob o ponto de vista do rendimento, desprezando, portanto, aspectos relevantes do bem-estar ligados ao acesso a serviços e à melhoria do conforto do domicílio, que, como se sabe, tem melhorado para todas as faixas de renda de forma sustentada no longo prazo, independentemente das características da conjuntura econômica.

Adotou-se a chamada abordagem da linha de pobreza. São definidos como pobres os indivíduos cuja renda familiar per capita é inferior ao valor que corres-
Correspondendo a cerca de 400 mil pessoas.

2 Este texto foi redigido antes da divulgação dos resultados do suplemento da PNAD 2004, o que ocorreu em março de 2006. 
$3 \ldots \ldots \ldots \ldots$ 3 Ver, por exemplo, Néri (2005), que, utilizando uma linha de pobreza única de $\mathrm{R} \$ 115,00$ para todo o País, verificou uma redução da proporção de pobres de $27 \%$, em 2003, para 25,1\%, em 2004; e Hoffman (2006), utilizando linhas de pobreza únicas de $\mathrm{R} \$ 150,00$ ou de $\mathrm{R} \$ 75,00$, estima que a proporção de pobres teria declinado de $37,5 \%$ para $34,6 \%$, no primeiro caso, e de $16,2 \%$ para $13,8 \%$, no segundo caso. ponderia ao necessário para atender a todas as necessidades básicas (alimentação, habitação, transporte, saúde, lazer, educação, etc.), enquanto se define como indigentes aqueles cuja renda familiar per capita é inferior ao valor necessário para atender tão-somente às necessidades básicas de alimentação (linha de indigência).

Para a obtenção dos indicadores de insuficiência de renda, foram utilizadas 23 linhas de pobreza e 23 linhas de indigência diferenciadas, de modo a levar em conta a diversidade de custo de vida entre áreas urbanas e rurais, assim como entre as regiões brasileiras. Como exemplo, a linha de pobreza mais alta, relativa à metrópole de São Paulo, foi de R \$250,79, ao passo que a mais baixa se referiu às áreas rurais de Minas Gerais/Espírito Santo, R $\$ 69,75$ (valores por pessoa/mês). A metodologia para determinação dessas linhas é a adotada por Rocha (1997), e as considerações metodológicas sobre a forma de determinação e atualização desses parâmetros são apresentadas no Anexo A.

Dependentes do nível e da distribuição da renda, e medidos com base nas chamadas linhas de pobreza e de indigência, os indicadores de pobreza e de indigência têm suscitado interesse cres- cente a cada divulgação da PNAD. Isso porque, pelo menos em termos do objetivo a alcançar, a sociedade brasileira dá sinais de priorizar a garantia do atendimento das necessidades básicas de todos os cidadãos, o que significa eliminar a pobreza absoluta. Embora estreitamente dependentes da conjuntura econômica - e nesse sentido, o forte crescimento do PIB em 2004 teve efeitos positivos sobre os níveis de emprego e renda das famílias -, os indicadores de pobreza e indigência vêm sendo favoravelmente afetados pelas políticas públicas relativas a aposentadorias e pensões, assim como pelos novos mecanismos de transferência de renda focalizados nos mais pobres. Nesse sentido, em contraponto com 2003, os resultados da PNAD foram especialmente auspiciosos, mostrando inequívoca redução da pobreza e da indigência em nível nacional, mesmo utilizando diversas metodologias de mensuração. ${ }^{3}$

Os resultados da PNAD 2004 não revelaram tão-somente redução da pobreza e da indigência, mas uma queda significativa da desigualdade de rendimentos. Esse fato se reveste de importância, uma vez que, como se sabe, a relativamente elevada incidência de pobreza e de indi- 
gência no Brasil não se deve estritamente ao nível de renda no País, mas às conhecidas características de extrema desigualdade na sua distribuição. Segundo evidências também derivadas da PNAD, a redução da pobreza em 2004 se deveu tanto ao aumento da renda, mas, principalmente, a melhorias distributivas. ${ }^{4}$

As seções que se seguem visam, inicialmente, destacar alguns resultados básicos da PNAD relativos à redução da pobreza e da indigência em 2004, no que tange ao seu rebatimento espacial. Em seguida, enfocam-se alguns aspectos de como as melhorias distributivas operaram no mercado de trabalho e através das transferências de renda, tendo por base as características de formação de renda das famílias. ${ }^{5}$

\section{2_A queda da proporção de pobres e de indigentes}

Os resultados de rendimento familiar per capita revelam redução inequívoca da pobreza e da indigência. A proporção de pobres na população brasileira cai de $35,6 \%$, em 2003, para $33,2 \%$, em 2004, o que corresponde a 57,7 milhões de pessoas pobres neste último ano - menos
2,4 milhões de pessoas do que em 2003, ao passo que a proporção de indigentes passa de $10 \%$ para $8 \%$, significando 13,9 milhões de indigentes em setembro de 2004 (menos 3,0 milhões de pessoas do que em 2003). ${ }^{6}$ A redução de cerca de dois pontos percentuais em ambas as proporções é o melhor resultado verificado desde o Plano Real, quando houve uma conjunção propícia de fatores, ensejando redução drástica da proporção de pobres de $44,1 \%$ para $33,2 \%$. O Gráfico 1 permite visualizar a tendência evolutiva da pobreza e da indigência. No caso da pobreza, as oscilações ocorridas no período 1996-2004 fazem com que os ganhos realizados em 2004 tragam a proporção praticamente ao nível observado em 1995. Em relação à indigência, a tendência mais sustentada de redução da proporção (só nos anos de 2001 e 2003 houve aumento da proporção de indigentes) permitiu que o resultado de 2004 tivesse sido o mais favorável jamais alcançado no País. Embora uma queda mais rápida e mais acentuada dos indicadores fosse desejável, os resultados mais favoráveis em relação à indigência indicam que, como desejável, as situações mais críticas estão sendo resolvidas primeiro.
4 Barros, Carvalho Franco (2006) estimam que a pobreza extrema teria declinado de $14,5 \%$, em 2003, para $12,3 \%$, em 2004, tanto graças ao aumento da renda, responsável por $27 \%$ da redução, como pela queda da desigualdade de rendimentos, que explica os $73 \%$ restantes.

5 Sempre que forem feitas comparações entre os resultados de 2003 e 2004, utilizar-se-ão dados compatibilizados, isto é, excluindo a região Norte rural em 2004.

6 Vale lembrar que os indigentes são um subconjunto de pobres e que, portanto, esses valores não são cumulativos. 
Gráfico 1_Proporção de Pobres e Indigentes de 1990-2004, Brasil

Como a PNAD é uma amostra, a divulgação de resultados apresenta limitações de detalhamento. Os resultados dos Anexos $\mathrm{B}$ e C são apresentados ao nível máximo de desagregação possível com base nos microdados de uso público. Todas as comparações entre 2003 e 2004 estão harmonizadas, isto é, não incluem os resultados para a região Norte rural (exceto Tocantins rural) que só passou a ser coberta pela amostra da PNAD em 2004.

8 Os resultados aqui apresentados são agregados, valendo-se de resultados mais detalhados obtidos para 54 áreas no País, já que a amostra da PNAD permite obtenção de estimativas para a maioria das Unidades da Federação, distinguindo situação urbana e rural, além das nove metrópoles e de Brasília.

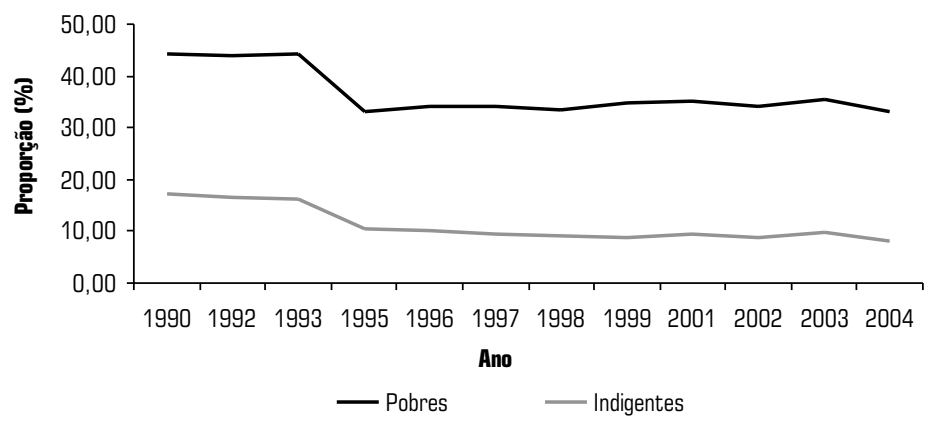

Fonte: IBGE, microdados da PNAD.

Tabela 1_Proporção de pobres e indigentes de 1990 a 2004 (\%) - Brasil*

\begin{tabular}{|c|c|c|c|c|c|c|c|c|c|c|c|c|}
\hline roporção (\%) & 1990 & 1992 & 1993 & 1995 & 1996 & 1997 & 1998 & 1999 & 2001 & 2002 & 2003 & 2004 \\
\hline obres & 44,19 & 44,00 & 44,09 & 33,23 & 34,13 & 34,09 & 33,43 & 34,95 & 35,03 & 33,99 & 35,59 & 33,21 \\
\hline 14. & 17,38 & 16,64 & 16,10 & 10,40 & 10,15 & 9,38 & 9,06 & 8,74 & 9,55 & 8,68 & 9,96 & 8,00 \\
\hline
\end{tabular}

(*) Exceto região Norte rural.

Fonte: IBGE, microdados da PNAD.

Os Anexos B e C apresentam, respectivamente, os resultados completos dos indicadores de renda relativos de indigência e pobreza, tanto de 2003 como de 2004. Reúnem o conjunto relevante de indicadores, e não apenas as proporções e os números de pobres e indigentes como mencionado no texto, e os resultados são apresentados por Unidade da Federação segundo estratos urbano, rural e metropolitano, ${ }^{7}$ de forma a permitir distinguir situações particulares que fre- qüentemente se distanciam daquelas observadas para os grandes agregados.

\section{3_A espacialização da pobreza e da indigência}

Embora a tendência de redução das proporções entre 2003 e 2004 tenha sido bastante robusta, ocorrendo melhoria do indicador para a quase totalidade das áreas de amostragem da PNAD, ${ }^{8}$ a magnitude dessa redução é muito diferenciada, especialmente em relação à proporção de pobres. 


\section{1_A evolução diferenciada} entre áreas metropolitanas, urbanas e rurais

Considerando separadamente as áreas metropolitanas, urbanas e rurais, a melhoria em 2004 foi mais tênue nas áreas metropolitanas, o que na verdade tem sido uma tendência ao longo de toda a década de
1990, com exceção do período imediatamente após o Plano de Estabilização (Gráficos 2 e 3). Isso significou convergência das proporções, isto é, uma redução das diferenças nas três áreas, no que concerne tanto às proporções de pobres como às de indigentes.

\section{Gráfico 2_Proporção de pobres de 1990-2004, por Estrato}

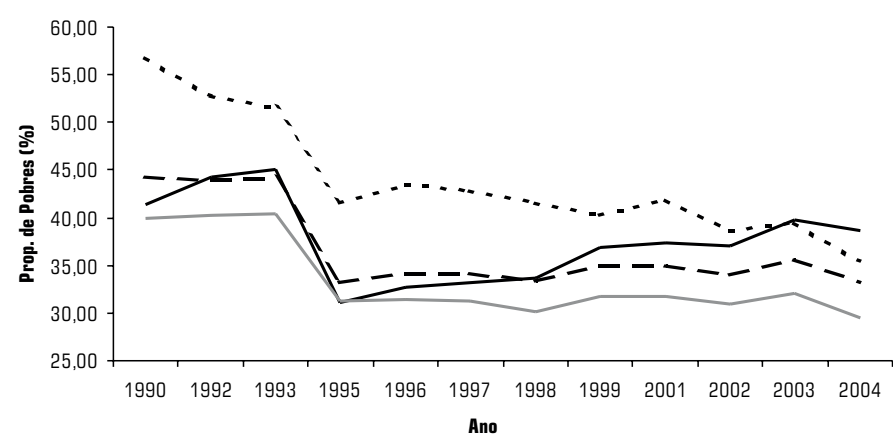

- - Brasil - Metropolitano U Urbano - - - Rural

Fonte: IBGE, microdados da PNAD.

\section{Gráfico 3_Proporção de indigentes de 1990-2004, por Estrato}

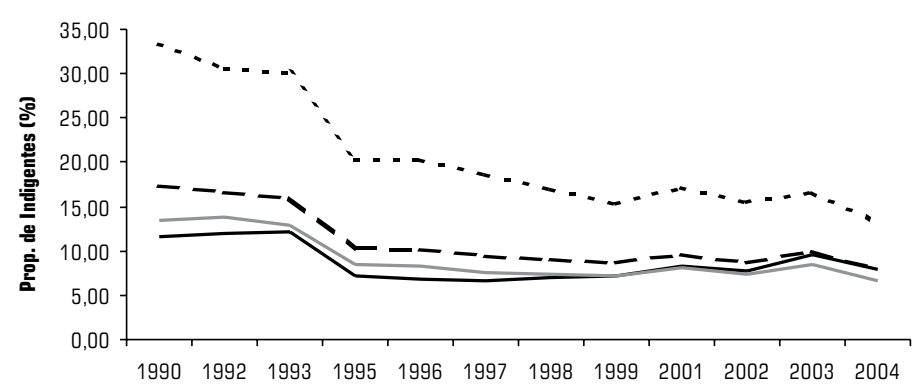

Ano

Fonte: IBGE, microdados da PNAD.

$$
\text { - - Brasil Metropolitano Urbano - - - - Rural }
$$


Tabela 2_Evolução da proporção de indigência e pobreza - 1992, 2003 e 2004

\begin{tabular}{l|c|c|c|c|c|c}
\multirow{2}{*}{ Brasil e Estratos } & \multicolumn{3}{|c|}{ Pobres (\%) } & \multicolumn{3}{c}{ Indigentes (\%) } \\
\cline { 2 - 7 } & $\mathbf{1 9 9 2}$ & $\mathbf{2 0 0 3}$ & $\mathbf{2 0 0 4}$ & $\mathbf{1 9 9 2}$ & $\mathbf{2 0 0 3}$ & $\mathbf{2 0 0 4}$ \\
\hline Metropolitano & 44,3 & 39,8 & 38,7 & 11,9 & 9,5 & 7,9 \\
\hline Urbano & 40,2 & 32,1 & 29,5 & 13,9 & 8,4 & 6,6 \\
\hline Rural* & 52,7 & 39,5 & 35,4 & 30,5 & 16,6 & 13,3 \\
\hline Brasil* . . . . . . . . . . & $\mathbf{4 4 , 0}$ & $\mathbf{3 5 , 6}$ & $\mathbf{3 3 , 2}$ & $\mathbf{1 6 , 6}$ & $\mathbf{1 0 , 0}$ & $\mathbf{8 , 0} \ldots$
\end{tabular}

$\left(^{*}\right)$ Exceto região Norte rural.

Fonte: IBGE, microdados da PNAD.

Naturalmente a queda mais sustentada, e também mais acentuada, das proporções de pobres e de indigentes nas áreas rurais, aliada à redução da população rural, fazem com que a pobreza e a indigência no Brasil sejam crescentemente fenômenos urbanos e metropolitanos. De 2003 a 2004, a participação dos indigentes e dos pobres rurais no total de indigentes e pobres no Brasil continuou a declinar - pobres rurais representam $15,3 \%$ dos pobres brasileiros, e os indi- gentes rurais $24 \%$ dos indigentes, o que é o resultado de uma trajetória que altera radicalmente a situação que se tinha no início da década de noventa (Tabela 3). Naturalmente os 3,3 milhões de indigentes rurais constituem uma clientela prioritária para atendimento pelas políticas públicas, porque não somente apresentam condições críticas de renda, mas também as conhecidas carências de acesso a serviços básicos a que são submetidos os mais pobres em áreas rurais.

\section{Tabela 3 Evolução da participação na indigência e na pobreza brasileira} segundo estratos - 1992, 2003 e 2004

\begin{tabular}{|c|c|c|c|c|c|c|}
\hline \multirow{2}{*}{ Estratos } & \multicolumn{3}{|c|}{ Indigência (\%) } & \multicolumn{3}{|c|}{ Pobreza (\%) } \\
\hline & 1992 & 2003 & 2004 & 1992 & 2003 & 2004 \\
\hline Metropolitano & 22,2 & 30,0 & 30,9 & 31,2 & 35,0 & 36,3 \\
\hline Urbano & 40,6 & 45,7 & 45,1 & 44,5 & 48,8 & 48,4 \\
\hline Rural* & 37,2 & 24,3 & 24,0 & 24,3 & 16,2 & 15,3 \\
\hline Brasil* & 100,0 & 100,0 & 100,0 & 100,0 & 100,0 & 100,0 \\
\hline
\end{tabular}

(*) Exceto região Norte rural.

Fonte: IBGE, microdados da PNAD. 


\section{2_A evolução diferenciada entre metrópoles}

Os resultados apresentados para o estrato metropolitano decorrem da agregação dos dados obtidos para nove metrópoles brasileiras, além de Brasília. Como os resultados metropolitanos são uma média dos resultados das metrópoles, ponderados pelo peso populacional de cada uma, São Paulo, com uma população de 19,2 milhões, ou $34 \%$ da população metropolitana brasileira, tem importância determinante sobre os resultados agregados.
Nesse sentido, o desempenho adverso da metrópole paulista na redução da pobreza entre 2003 e 2004 afetou desfavoravelmente o resultado para o conjunto de metrópoles. No entanto, é importante notar que as diversas metrópoles tiveram desempenhos diferenciados nesse particular, dependendo de diversos fatores, particularmente condições locais de dinamismo econômico e evolução local do custo de vida para os pobres. A Tabela 4 mostra a evolução verificada quanto à proporção de pobres nas metrópoles.

Tabela 4_Proporção, número e participação 2003 e 2004 por metrópole

\begin{tabular}{|c|c|c|c|c|c|c|c|c|c|}
\hline \multirow{2}{*}{ Metrópoles e Brasil } & \multicolumn{3}{|c|}{ Proporção de pobres (\%) } & \multicolumn{3}{|c|}{ Número de pobres (mil) } & \multicolumn{3}{|c|}{ Participação (\%) } \\
\hline & 2003 & 2004 & $\Delta$ & 2003 & 2004 & $\Delta \%$ & 2003 & 2004 & $\Delta$ \\
\hline Belém & 45,4 & 40,3 & $-5,1$ & 803 & 783 & $-2,5$ & 3,7 & 3,7 & $-0,1$ \\
\hline Fortaleza & 49,2 & 48,9 & $-0,2$ & 1.544 & 1.579 & 2,2 & 7,3 & 7,5 & 0,2 \\
\hline Recife & 63,3 & 59,9 & $-3,4$ & 2.084 & 2.073 & $-0,6$ & 9,9 & 9,9 & 0,0 \\
\hline Salvador & 56,6 & 51,7 & $-5,0$ & 1.758 & 1.630 & $-7,3$ & 8,3 & 7,8 & $-0,5$ \\
\hline Belo Horizonte & 36,2 & 34,1 & $-2,1$ & 1.627 & 1.563 & $-3,9$ & 7,7 & 7,5 & $-0,2$ \\
\hline Rio de Janeiro & 34,5 & 33,6 & $-0,9$ & 3.666 & 3.558 & $-3,0$ & 17,4 & 17,0 & $-0,4$ \\
\hline São Paulo & 41,0 & 41,6 & 0,6 & 7.292 & 7.506 & 2,9 & 34,5 & 35,8 & 1,3 \\
\hline Curitiba & 26,2 & 22,4 & $-3,8$ & 765 & 680 & $-11,1$ & 3,6 & 3,2 & $-0,4$ \\
\hline Porto Alegre & 17,8 & 16,4 & $-1,4$ & 677 & 635 & $-6,2$ & 3,2 & 3,0 & $-0,2$ \\
\hline Brasília & 42,7 & 42,4 & $-0,3$ & 912 & 945 & 3,6 & 4,3 & 4,5 & 0,2 \\
\hline Total Metrópoles & 39,8 & 38,7 & $-1,1$ & 21.129 & 20.951 & $-0,8$ & 100,0 & 100,0 & - \\
\hline Total Brasil* & 35,6 & 33,2 & $-2,4$ & 60.363 & 57.698 & $-4,4$ & 35,00 & 36,31 & 1,31 \\
\hline
\end{tabular}


9 O conjunto de indicadores apresentados nos Anexos A e $B$ permitem verificar que, considerando os diferentes aspectos de pobreza conquanto insuficiência de renda, o desempenho de Curitiba e Belém foi melhor que o de Salvador no período.
Cabe notar, ainda, que não só entre as metrópoles, São Paulo foi uma exceção no que concerne ao comportamento desfavorável da evolução da pobreza entre 2003 e 2004. Considerando as áreas brasileiras que podem ser analisadas individualmente, tomando-se por base a amostra da PNAD (ver Anexos B e C), a metrópole de São Paulo foi uma das poucas que apresentou evolução adversa da pobreza. É interessante repertoriar quatro fatores explicativos desse resultado, colocando em contraponto a situação da metrópole de Salvador, que apresentou, nesse particular, o desempenho mais favorável em relação à proporção de pobres no período. ${ }^{9}$

a. fraca criação de postos de trabalho - a criação de postos de trabalho em São Paulo apresentou uma expansão de $1,9 \%$, bem aquém da média brasileira, de 3,3\%, e muito abaixo da verificada em Salvador, de 6,6\%, no mesmo período. A esse respeito cabe destacar que Salvador vem atraindo população em função dos novos pólos de dinamismo econômico, o que levou a um crescimento demográfico de 1,8\%. Em São Paulo, o arrefecimento do crescimento demográfico contribuiu para que o agravamento da po- breza não fosse ainda mais acentuado. $\mathrm{Na}$ verdade, reduziu-se a atratividade da metrópole aos migrantes, apesar das tradicionais redes de solidariedade que acolhem os recém-chegados, e da percepção positiva destes quanto às vantagens oferecidas por São Paulo em termos de qualidade de serviços públicos e mobilidade econômico-social ascendente.

b. evolução desfavorável do rendimento do trabalho - embora, para o conjunto do País, o rendimento médio do trabalho tenha ficado estável entre 2003 e 2004, no conjunto das metrópoles houve queda. Isso se deu em função do desempenho adverso das metrópoles com peso relativo mais importante, São Paulo e Rio de Janeiro. Cabe observar que, embora o rendimento do trabalho seja tradicionalmente mais elevado em São Paulo do que nas demais metrópoles, o que representa um atrativo ponderável para os trabalhadores menos qualificados, a evolução entre 2003 e 2004 foi muito adversa - queda de $5,3 \%$ do rendimento médio dos ocupados em São Paulo em relação a 2003 (Tabela 5). Quando se consideram os rendimen- 
tos por nível de qualificação, a evolução para os trabalhadores com menor escolaridade foi mais favorável, ficando praticamente estável, tanto em Salvador como em São Paulo. No entanto, a queda do número de ocupados com menos de oito anos de escolaridade em São Paulo - que ainda representam espantosos 31\% dos ocupados no núcleo urbano mais importante e avançado do País -, fez com que o rendimento total do trabalho desse grupo fosse reduzido em 1,5\% em termos reais, o que certamente teve algum impacto sobre a pobreza em São Paulo. Em Salvador, ainda que os trabalhadores menos qualificados (menos de oito anos de estudo) também venham perdendo participação na força de trabalho - o que é um fenômeno geral no País -, houve, ao contrário de São Paulo, algum aumento do número de ocupados, e, em conseqüência, aumento do seu rendimento total em 2,9\%.

c. aumento relativamente forte do custo de vida dos pobres - os valores utilizados como linhas de pobreza (Anexo A) levam em conta custos de vida diferenciados entre metrópo- les. Desse modo, os valores para São Paulo, refletindo a estrutura de consumo dos pobres naquela metrópole, e os preços praticados localmente, são sempre os mais altos do Brasil, o que é compatível com necessidades e custos mais elevados de despesas, tais como habitação, vestuário, transporte e comunicação, na metrópole paulista. De 2003 para 2004, a linha de pobreza de São Paulo apresentou aumento relativamente forte, $+5,29 \%$, passando de $\mathrm{R} \$ 238,20$ para $\mathrm{R} \$ 250,79$. Em Salvador, a linha de pobreza, que se situa a um nível bem mais baixo, também se elevou, mas em grau mais moderado $(+3,75 \%)$, passando de $\mathrm{R} \$ 174,64$ para $\mathrm{R} \$ 181,19$. Vale destacar que o resultado para Salvador foi afetado pela deflação do preço dos alimentos entre 2003 e 2004 (-1,3\%).

d. o menor impacto positivo de valores fixados com base em parâmetros nacionais - como se viu, o custo de vida é mais baixo em Salvador do que em São Paulo. Em conseqüência, o impacto na redução da pobreza de benefícios cujos valores são fixados nacionalmente - tanto os previdenciários e assistenci- 
ais como os associados às transferências dos novos programas no âmbito do Bolsa-Família - é necessariamente menor na metrópole paulista. À guisa de ilustração, o salário mínimo, o qual se iguala à maioria de benefícios previdenciários (pensões e aposentadorias) e assistenciais (benefícios de prestação continuada a idosos e a portadores de deficiência), era de $\mathrm{R} \$ 260,00$ em setembro de 2004, superior em apenas 3,7\% à linha de pobreza em
São Paulo. Em contrapartida, o salário mínimo era 43,5\% superior à linha de pobreza de Salvador $(\mathrm{R} \$ 181,19)$ na mesma data.

A Tabela 5 apresenta de forma sintética indicadores que explicam a evolução adversa da pobreza em São Paulo, permitindo comparar com os resultados verificados em Salvador. Naturalmente, estes indicadores refletem também diferenças de dinamismo econômico das duas metrópoles no período em questão, cuja análise transcende o objetivo desta nota.

Tabela 5_ Indicadores selecionados - São Paulo e Salvador - 2003 e 2004

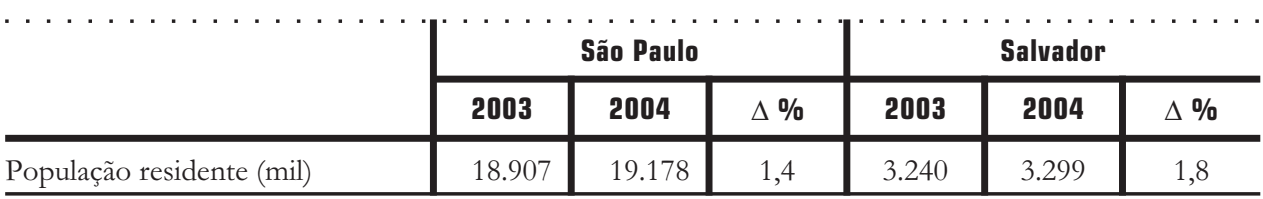

\begin{tabular}{l|r|r|r|r|r|r}
\hline Ocupados (mil)** \\
\hline Total & $\mathbf{7 . 9 6 0}$ & $\mathbf{8 . 1 1 3}$ & $\mathbf{1 , 9}$ & $\mathbf{1 . 3 2 8}$ & $\mathbf{1 . 4 1 6}$ & $\mathbf{6 , 6}$ \\
\hline Com menos de 8 anos de estudo & 2.539 & 2.486 & $-2,1$ & 514 & 526 & 2,2 \\
\hline
\end{tabular}

\begin{tabular}{|c|c|c|c|c|c|c|}
\hline \multicolumn{7}{|l|}{ Rendimento Médio $\left(\mathrm{R} \$^{*}\right)$} \\
\hline Total & $1.082,82$ & $1.025,37$ & $-5,3$ & 630,72 & 609,34 & $-3,4$ \\
\hline Com menos de 8 anos de estudo & 550,22 & 553,82 & 0,7 & 299,56 & 301,51 & 0,7 \\
\hline
\end{tabular}

Rendimento Total (R\$ milhões*)

\begin{tabular}{|c|c|c|c|c|c|c|}
\hline Total & 8.619 & 8.319 & $-3,5$ & 838 & 863 & 3,0 \\
\hline Com menos de 8 anos de estudo & 1.397 & 1.377 & $-1,5$ & 154 & 159 & 2,9 \\
\hline
\end{tabular}

(*) A preços de setembro de 2004 (Deflator INPC).

$(* *)$ Exclui aqueles em atividades de próprio consumo e próprio uso.

Fonte: IBGE, microdados da PNAD. 


\section{3_Desigualdades regionais \\ e a pobreza nordestina}

Apesar dos resultados favoráveis de redução da pobreza e da indigência também no Nordeste - a proporção de pobres caiu de $51,9 \%$ da população total em 2003 para $48,5 \%$ em 2004 (de 25,2 milhões de pessoas para 24,0 milhões) e a de indigentes de $18,7 \%$ para $14,9 \%$ (de 9,1 milhão de pessoas em 2003 para 7,3 milhões em 2004) -, a posição adversa da região no contexto do País permanece praticamente imutável (Tabela 6). $\mathrm{Na}$ verdade, a situação relativa do Nordeste, no que concerne à pobreza e à indigência, não tem se alterado também quando se toma o horizonte de longo prazo. Considerando os anos 1992 a 2004, a participação do número de pobres e indigentes nordestinos no total de pobres e indigentes brasileiros ficou pra ticamente estável em torno de, respectivamente, $42 \% \mathrm{e}$ $54 \%$ (Gráfico 4). Nesse sentido, não se verificou, no que concerne à renda, a redução da desvantagem relativa do Nordeste, como vem ocorrendo em relação a outras carências notórias, tais como educação, acesso à água e à eletricidade, além de nível de conforto dos domicílios.

\section{4_Mudanças no mercado de trabalho e escolaridade}

O desempenho do mercado de trabalho entre 2003 e 2004 foi, sem dúvida, favorável. Houve aumento robusto da taxa de ocupação, que significou a criação de 2,7 milhões de postos de trabalho. Verificouse, concomitantemente, expansão forte do emprego e menos informalidade, já que a expansão dos ocupados por conta própria foi moderada, os empregos com carteira e sem carteira tiveram taxa de crescimento semelhantes, e houve redução da proporção dos ocupados com rendimento zero, além dos ocupados em atividades para próprio consumo e próprio uso. No entanto, esses bons resultados se fizeram acompanhar pela estagnação do rendimento do trabalho, que, em termos reais, se manteve ao mesmo nível de 2003. Nesse sentido, o aumento da massa salarial se deveu exclusivamente ao aumento da ocupação. A Tabela 7 sintetiza esses resultados.

Os dados da PNAD 2004 relevam ainda que o aumento de 2,7 milhões de postos de trabalho significou alteração na composição do contingente de ocupados: houve a substituição de trabalhadores menos qualificados por mais qualificados. Assim, deixaram de estar ocupados 436 mil trabalhadores com menos de 8 anos de estudo, enquanto cresceu em 3,1 milhões o número de ocupados com mais de oito anos de escolaridade. Em particular, o contingente de ocupados com 11 anos ou mais de escolaridade, isto é, com pelo menos o segundo grau conclú́do, aumentou quase $9 \%$, chegando a pouco mais de 34\% do total de ocupados. A Tabela 8 ilustra essa evolução. 
Tabela 6_ As proporções do Nordeste comparadas às do Brasil em 1992, 2003 e 2004 e respectivas participações (\%)

\begin{tabular}{l|c|c|c|c|c|c}
\multirow{2}{*}{ Brasil, Nordeste e Estratos } & \multicolumn{3}{c}{ Pobres } & \multicolumn{3}{c}{ Indigentes } \\
\cline { 2 - 7 } & $\mathbf{1 9 9 2}$ & $\mathbf{2 0 0 3}$ & $\mathbf{2 0 0 4}$ & $\mathbf{1 9 9 2}$ & $\mathbf{2 0 0 3}$ & $\mathbf{2 0 0 4}$ \\
\hline Proporção (\%) Nordeste & $\mathbf{6 3 , 9}$ & $\mathbf{5 1 , 9}$ & $\mathbf{4 8 , 5}$ & $\mathbf{3 1 , 3}$ & $\mathbf{1 8 , 7}$ & $\mathbf{1 4 , 9}$ \\
\hline Metropolitano & 61,4 & 56,5 & 53,6 & 22,6 & 17,7 & 14,3 \\
\hline Urbano & 62,5 & 49,9 & 47,0 & 25,6 & 15,9 & 12,6 \\
\hline Rural & 66,9 & 52,4 & 47,6 & 42,9 & 24,4 & 19,8 \\
\hline
\end{tabular}

Número (mil)

\begin{tabular}{|c|c|c|c|c|c|c|}
\hline Nordeste & 25.615 & 25.220 & 24.001 & 12.562 & 9.079 & 7.393 \\
\hline Brasil & 61.607 & 60.363 & 57.698 & 23.296 & 16.890 & 13.895 \\
\hline Participação NE no Brasil (\%) & 41,6 & 41,8 & 41,6 & 53,9 & 53,8 & 53,2 \\
\hline
\end{tabular}

Fonte: IBGE, microdados da PNAD.

Gráfico 4_ Evolução da participação do Nordeste no número total de pobres e de indigentes no Brasil - 1992-2004

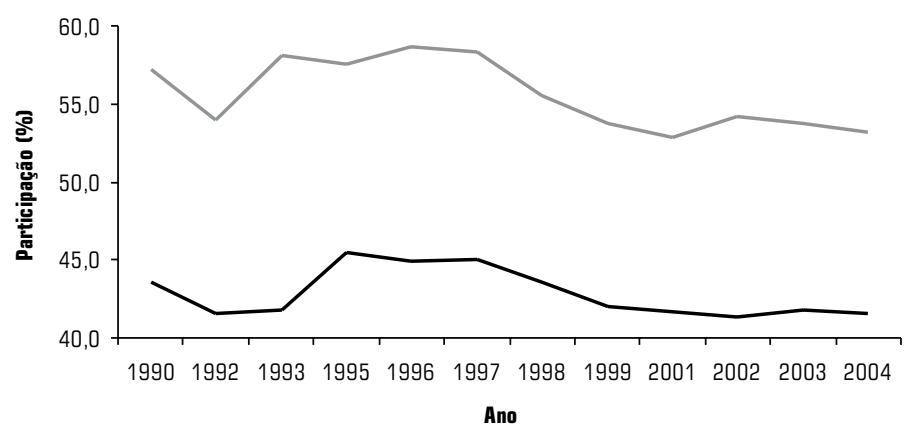

- Pobres $\quad$ Indigentes

Fonte: IBGE, microdados da PNAD. 
Tabela 7 Indicadores básicos do mercado de trabalho - 2003-2004

\begin{tabular}{|c|c|c|c|}
\hline Indicadores & 2003 & 2004 & $\Delta \%$ 2003-2004 \\
\hline Número de Ocupados & 80.163 .481 & 82.816 .911 & 3,3 \\
\hline Empregados & 49.755 .914 & 52.684 .776 & 5,9 \\
\hline Com carteira & 30.949 .941 & 32.754 .239 & 5,8 \\
\hline Sem carteira & 18.805 .973 & 19.930 .537 & 6,0 \\
\hline Conta própria & 17.909 .563 & 18.015 .385 & 0,6 \\
\hline Empregadores & 3.363 .202 & 3.430 .993 & 2,0 \\
\hline Não remunerados & 5.664 .891 & 5.407 .550 & $-4,5$ \\
\hline Próprio Consumo/Uso & 3.469 .911 & 3.278 .207 & $-5,5$ \\
\hline Rendimento Médio $(\mathrm{R} \$)^{1}$ & 733,63 & 732,97 & $-0,09$ \\
\hline Massa Salarial (R\$ milhões $)^{1}$ & $52.108,46$ & $54.335,79$ & $4,27$. \\
\hline
\end{tabular}

(*) Exceto região Norte rural.

(1) A preços de setembro de 2004 (Deflator INPC).

Fonte: IBGE, microdados da PNAD.

Nota: O rendimento médio não leva em consideração os ocupados sem rendimento (os não-remunerados e os ocupados em produção para próprio consumo e próprio uso).

\section{Tabela 8_ Ocupados segundo anos de estudo - 2003-2004}

\begin{tabular}{|c|c|c|c|}
\hline Anos de Estudo & 2003 & 2004 & $\Delta \%$ 2003-2004 \\
\hline Menos de 8 anos & 40.598 .830 & 40.163 .115 & $-1,07$ \\
\hline Sem instrução e menos de 1 ano & 8.214 .764 & 8.075 .260 & $-1,70$ \\
\hline 1 a 3 anos & 9.871 .051 & 9.585 .291 & $-2,89$ \\
\hline 4 a 7 anos & 22.513 .015 & 22.502 .564 & $-0,05$ \\
\hline 8 anos e mais & 39.300 .024 & 42.412 .930 & 7,92 \\
\hline 8 a 10 anos & 13.202 .754 & 13.996 .917 & 6,02 \\
\hline 11 anos ou mais & 26.097 .270 & 28.416 .013 & 8,89 \\
\hline Sem declaração & 264.627 & 240.866 & $-8,98$ \\
\hline Total. & 80.163 .481 & 82.816 .911 & 3,31 \\
\hline \multicolumn{4}{|c|}{ Fonte: IBGE, microdados da PNAD. } \\
\hline \multicolumn{4}{|c|}{$\begin{array}{l}\text { Nota: Resultados de } 2004 \text { ajustados para ser compatíveis com os de } 2003 \text {, isto é, excluindo a região Norte rural (exceto } \\
\text { Tocantins). Em 2004, o total de pessoas ocupadas no Brasil considerando toda a área rural da região Norte foi de } \\
84.596 .294 \text {. }\end{array}$} \\
\hline
\end{tabular}


É interessante verificar como o rendimento médio total constante e a mudança na composição dos ocupados se rebateram sobre os rendimentos segundo níveis de escolaridade (Tabela 9). Por um lado, ocorreu algum aumento do rendimento médio para os menos qualificados, justamente aqueles com até oito anos de estudo, que perderam participação no mercado de trabalho. Em contrapartida, o rendimento médio para os ocupados com maior escolaridade reduziuse em termos reais entre $2,5 \%$ e $3 \%$, no período 2003 e 2004.

A conjunção de mudanças da composição do contingente de ocupados e da distribuição dos rendimentos de trabalho segundo nível de escolaridade tem algumas implicações, a saber: a. Ocorreu alguma redução dos retornos à educação que, como se sabe, são excepcionalmente elevados no Brasil. Esses retornos elevados decorrem da desigualdade de escolaridade e do embate entre demanda por mão-deobra qualificada ante o baixo nível médio de escolaridade da PEA. Tal redução do "prêmio" por educação para os níveis de escolaridade superiores ao ciclo básico de oito anos pode ser um fenômeno temporário associado à retomada da ocupação após um período caracterizado por baixa demanda de mão-de-obra e/ou à entrada no mercado de trabalho de trabalhadores "inexperientes".

Tabela 9_Rendimento médio do trabalho (R\$)* segundo nível de escolaridade - 2003-2004

\begin{tabular}{|c|c|c|c|}
\hline Anos de Estudo & 2003 & 2004 & $\Delta \% 03-04$ \\
\hline Sem instrução ou menos de 1 ano & 233,17 & 237,46 & 1,84 \\
\hline de 1 a 3 anos & 304,10 & 304,85 & 0,25 \\
\hline de 4 a 7 anos & 408,55 & 415,45 & 1,69 \\
\hline de 8 a 10 anos & 514,23 & 498,84 & $-2,99$ \\
\hline com 11 anos ou mais & $1.227,12$ & $1.195,90$ & $-2,54$ \\
\hline Sem declaração & 428,42 & 443,68 & 3,56 \\
\hline Total & 668,11 & 672,55 & 0,66 \\
\hline
\end{tabular}

${ }^{*}$ ) Todos os trabalhos, inclusive rendimento zero. Quando se consideram apenas os rendimentos positivos, o rendimento médio de 2003 e 2004 é virtualmente idêntico (R\$ 733,00 a preços de 2004).

(**) A preços de setembro de 2004 (Deflator INPC).

Fonte: IBGE, microdados da PNAD. 
b. Considerando que, quanto mais anos de estudo, maior tende a ser a produtividade do trabalho, teria havido aumento de eficiência do sistema produtivo não repassado sob forma de rendimento para o trabalhador, o que, considerando esse aspecto específico sem alterações dos outros determinantes relevantes, ${ }^{10}$ representa um estímulo para a expansão sustentada da atividade econômica.

c. A redução do rendimento médio dos trabalhadores mais qualificados e o aumento do rendimento para aqueles com menor qualificação resultaram em diminuição da desigualdade de rendimentos.

Cabe observar ainda como esse conjunto de mudanças afetou a distribuição dos rendimentos (Tabela 10). Houve ganhos para os ocupados que percebiam em torno do salário mínimo, o que foi, em parte, determinado pelo aumento nominal de $8,3 \%$ do SM em maio de 2004, permitindo um ganho real de $2,25 \%$ na data de referência da PNAD. ${ }^{11}$ Verifica-se que os trabalhadores com rendimentos nas faixas de mais de 1 a 3 salários mínimos tiveram ganho real significativo, o que levou necessariamente à redução da desigualdade de rendimentos, já que esse aumento real foi potencializado pelo grande número de trabalhadores ocupados com rendimento nessa faixa, 32,6 milhões em 2004 ou 38,6\% do total de ocupados no Brasil naquele ano. Assim, embora os rendimentos médios nas faixas acima de dez salários mínimos tenham tido aumentos reais muito maiores, o impacto sobre a distribuição foi atenuado em razão do relativamente pequeno número de ocupados nessas faixas $(3,7 \%$ dos ocupados em 2004). Em conseqüência, o Gini do rendimento do trabalho caiu de 0,554, em 2003, para 0,547, em 2004,12 o que, não obstante esteja longe de resolver o problema crítico da desigualdade de renda no Brasil, constitui avanço na direção desejada. Soares (2006), em excelente trabalho sobre a evolução da desigualdade no longo prazo, mostra que a redução da desigualdade no rendimento do trabalho foi responsável por $71 \%$ da redução da desigualdade da renda domiciliar per capita verificada entre 2003 e 2004.13

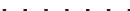

10 Coeteris paribus.

11 O deflator utilizado é o INPC/IBGE. A data de referência da PNAD é setembro de cada ano. 12 IBGE/PNAD, Tabelas de Indicadores Harmonizados da Divulgação da PNAD 2004. Esse valor do Gini considera apenas os rendimentos positivos.

13 A renda domiciliar per capita, ou a renda familiar per capita, é a variável mais importante quando se trata de verificar o grau de desigualdade de rendimentos como determinante do bem-estar, já que considera o resultado da repartição solidária de todos os rendimentos no âmbito do domicílio ou da família, levando em conta toda a população. 
Tabela 10_ Rendimento médio do trabalho das pessoas ocupadas segundo faixas de salário mínimo - 2003 e 2004

\begin{tabular}{|c|c|c|c|}
\hline \multirow{2}{*}{ Classes de Rendimento Mensal } & \multicolumn{3}{|c|}{ Rendimento Médio* } \\
\hline & 2003 & $2004 * *$ & $\Delta \%$ 2003-2004 \\
\hline Total & 648,14 & 646,96 & $-0,18$ \\
\hline Até $1 / 2 \mathrm{SM}$ & 79,77 & 78,82 & $-1,20$ \\
\hline Mais de $1 / 2$ a $1 \mathrm{SM}$ & 222,90 & 224,32 & 0,63 \\
\hline Mais de 1 a 2 SM & 374,75 & 390,42 & 4,18 \\
\hline Mais de 2 a 3 SM & 616,31 & 635,50 & 3,11 \\
\hline Mais de 3 a 5 SM & $1.004,93$ & 984,73 & $-2,01$ \\
\hline Mais de 5 a $10 \mathrm{SM}$ & $1.803,52$ & $1.846,45$ & 2,38 \\
\hline Mais de 10 a 20 SM & $3.419,90$ & $3.680,83$ & 7,63 \\
\hline Mais de $20 \mathrm{SM}$ & $7.987,94$ & $9.122,39$ & 14,20 \\
\hline
\end{tabular}

(*) A preços de setembro de 2004 (Deflator INPC).

(**) O cálculo do rendimento dos ocupados para 2004 inclui toda região Norte rural.

Fonte: IBGE, Pesquisa Nacional por Amostra de Domicílios.

Nota: Os limites das faixas de rendimento não têm o mesmo valor real nos dois anos graças ao ganho real do salário mínimo de $10 \%$ entre setembro de 2003 e setembro de 2004. Os valores dos rendimentos médios estão expressos a preços constantes de setembro de 2004

Apesar de o rendimento médio do trabalho ter ficado praticamente estável, a forte expansão da ocupação aliada ao aumento dos rendimentos na base da distribuição foram os principais determinantes para a redução da pobreza e da indigência entre 2003 e 2004. Embora o sistema de previdência e de assistência social, assim como os novos programas de transferência de renda no âmbito do Bolsa-Família, tenham contribuído nesse sentido, foi o comportamento do mercado de trabalho, como é desejável, o fator fundamental para o aumento da renda das famílias, levando à redução da pobreza e da indigência no período em questão. 


\section{5_Nível e composição da renda familiar}

A variável relevante quando se trata de medir pobreza sobre a ótica da renda é a renda familiar ou domiciliar per capita, que resulta da repartição solidária dos rendimentos de todas as origens (trabalho; aposentadorias; pensões; doações, transferências, aluguéis, juros, etc.) recebidos por todos os membros da família ou do domicílio.

Nesse sentido, a forma como evoluiu a composição da renda familiar fornece alguns elementos adicionais para compreender a redução da pobreza e da indigência entre 2003 e 2004. Para o conjunto das famílias brasileiras, a renda total cresceu em $4,5 \%$ nesse período, mas sua composição segundo origem da renda ficou praticamente inalterada, cabendo, no entanto, destacar dois aspectos.

\section{$1^{\circ}$ aspecto}

A renda do trabalho é - e não poderia deixar de ser - o componente principal da renda das famílias brasileiras, sendo responsável por pouco mais de $3 / 4$ da renda total, mesmo para as mais pobres (até $\mathrm{R} \$ 100,00$ de renda familiar per capita). $\mathrm{Na}$ verdade, a importância do trabalho como fonte de rendimento vai além, visto que parte ponderável das aposentadorias e pensões é apenas renda do trabalho dife- rida no tempo mediante mecanismos de previdência. $O$ aumento real de $4 \%$ no valor da renda total do trabalho entre 2003 e 2004 se deu, como visto anteriormente, em função da expansão da ocupação, já que o rendimento médio do trabalho permaneceu estável no período. Vale observar que, para as famílias mais pobres, a participação do trabalho na renda declina de $79,0 \%$, em 2003 , para $76,5 \%$, em 2004, em função da importância crescente das transferências monetárias.

\section{$2^{0}$ aspecto}

A renda oriunda de juros, rendimentos de capital e outros rendimentos aumentou em $58 \%$ sua participação de composição da renda das famílias entre 2003 e 2004. No entanto, sua importância permanece marginal no total da renda, passando de $1 \%$, em 2003, para 1,6\%, em 2004. ${ }^{14}$ Cabe destacar que a PNAD investiga esses rendimentos residuais diversos num único quesito, que inclui as transferências de renda focalizadas nas famílias mais pobres, com importância crescente no âmbito do gasto social brasileiro. Em setembro de 2004, o valor total das transferências realizadas no âmbito do Bolsa-Família, considerando também o conjunto de programas federais preexistentes, tais como Bolsa-Escola, Bolsa-Alimentação, Vale-Gás, PETI, etc., chegou a R \$ 509 milhões (Brasil, [s. d.]).

\footnotetext{
14 Como se sabe, juros e rendimentos de capital são informações difíceis de ser obtidas em inquéritos domiciliares, particularmente em pesquisas de objetivos múltiplos como a PNAD. Nesse sentido, é sabido que a PNAD subestima fortemente tais rendimentos, o que, no entanto, só prejudica a comparação da composição da renda ou do nível de desigualdade em anos subseqüentes, se houver mudança significativa da participação dos juros na renda total ou da sua taxa de subdeclaração.
} 
O segundo gráfico da Figura 1 ilustra como a composição da renda se altera conforme o nível de renda familiar. Para famílias com renda familiar per capita inferior a $\mathrm{R} \$ 100,00$, em 2004 , portanto correspondendo ao público-alvo dos programas federais de transferência de renda, a participação dos rendimentos que incluem essas transferências passou de $5,6 \%$, em 2003 , para $10,2 \%$, em $2004 .{ }^{15}$ Como essas famílias muito pobres certamente não recebem juros, o crescimento dessa rubrica se deve certamente aos novos programas de transferência de renda. A importância crescente das transferências levou a alguma perda de participação de outras rubricas na formação da renda dessas famílias, em particular a da renda do trabalho, que cai de $79 \%$, em 2003 , para 76,5, em 2004.

\footnotetext{
15 O valor de $\mathrm{R} \$ 100,00$

correspondia ao limite

superior da renda familiar per

capita para fins de seleção de

beneficiários para os "novos" programas de transferência de renda, já que os programas associados à LOAS utilizam 1/4 de salário mínimo ( $\mathrm{R} \$ 65,00$ em setembro de 2004) como limite máximo da RFPC.

16 A esse respeito, vale mencionar que Hoffmann
}

Finalmente vale a pena lembrar que, embora não tenhamos apresentado aqui uma medida da redução da pobreza em função das transferências, ${ }^{16}$ estas não beneficiaram somente os indivíduos que deixaram de ser pobres com a renda adicional, reduzindo o indicador de proporção, como também indivíduos que permaneceram pobres, mas tiveram melhoria da renda. Assim, o indicador denominado biato da renda mostra redução da intensidade da pobreza em relação à situação de 2003 para os indivíduos que permaneceram pobres em 2004, isto é, com renda familiar per capita abaixo da linha de pobreza. Os dados da PNAD 2004 revelam que ocorreu redução do hiato entre a renda dos pobres e o valor da linha de pobreza (Tabela 11). Enquanto em 2003 a renda média dos pobres correspondia a $53 \%$ ou pouco mais da metade do valor da linha de pobreza, faltando, portanto, 47\% para atingi-la, em 2004 essa diferença de renda reduziu-se para $44 \%$. Cabe observar que o efeito se deu em áreas urbanas, rurais e metropolitanas, aproximando o nível de intensidade da pobreza nas diferentes áreas do País. É especialmente importante a redução do número de famílias com renda zero, que, por natureza, constituem a população-alvo prioritária dos programas de transferência de renda do governo, de 1,8 milhão, em 2003, para 1,6 milhão, em 2004. 
Figura 1_Composição da renda familiar no Brasil - 2004

\section{TODAS AS FAMÍLIAS}

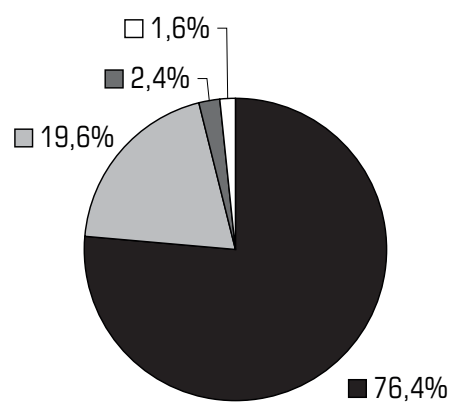

FAMÍLAa COM RENDA FAMÍLAR PER CAPITA $\leq$ R\$ 100

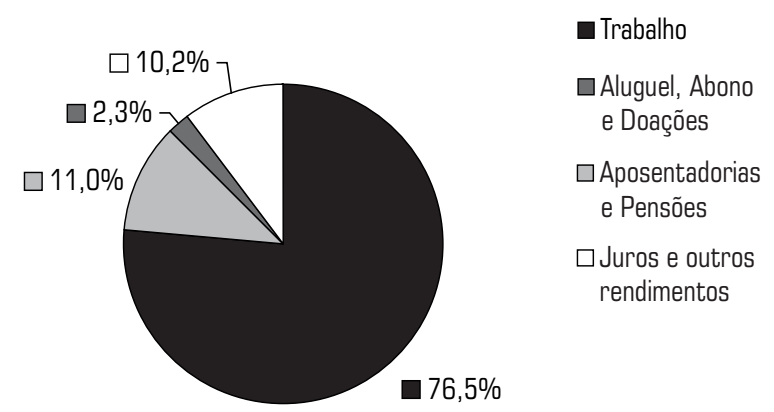

Fonte: IBGE/PNAD

Tabela 11_Razão do hiato da renda, segundo estratos - 2003 e 2004

\begin{tabular}{|c|c|c|}
\hline Brasil e Estratos & 2003 & 2004 \\
\hline Brasil & 0,47 & 0,44 \\
\hline Metropolitano & 0,48 & 0,46 \\
\hline Urbano & 0,46 & 0,44 \\
\hline Rural & 0,45 & 0,44 \\
\hline
\end{tabular}

Fonte: IBGE, microdados da PNAD.

\section{6_Considerações finais}

A redução da proporção de pobres e indigentes descrita acima, que ocorre na maioria das áreas que podem ser acompanhadas com a amostra da PNAD, foi determinada por diversos fatores, cujo impacto é diferenciado por área, e também conforme se considera a pobreza ou a indigência. Assim, a análise em detalhe revela agravamento da pobreza em algumas áreas, metrópole de São Paulo, por exemplo, como também manutenção de desigualdades entre áreas, como é o caso da manutenção da participação relativa da pobreza nordestina no âmbito do País. Vale, no entanto, fazer algumas considerações de ordem geral sobre os principais fatores determinantes da melhoria ocorrida, que foi, sem dúvida, a tendência dominante. 


\section{1_Criação de postos de trabalho}

Entre 2003 e 2004, foram criados cerca de 2,7 milhões de postos de trabalho, mas manteve-se a redução tendencial da ocupação para os indivíduos de baixa escolaridade (perda de 435.715 postos de trabalho para aqueles com menos de oito anos de estudo). Desse modo, a redução da pobreza e da indigência do ponto de vista do mercado de trabalho foi influenciada por dois fatores. O primeiro foi o aumento do rendimento médio na faixa de 1 a 3 salários mínimos, pagos aos trabalhadores que ingressam no mercado de trabalho com mais qualificação. O segundo fator resultou da própria característica "solidária" da formação da renda familiar, variável usada para medir pobreza e indigência: os membros da família, com qualificação e inserção diferenciada no mercado de trabalho, contribuem para o valor que é repartido igualmente, isto é, em base "per capita". Verificou-se, ainda, forte redução de pessoas ocupadas, mas sem rendimento $(-4,5 \%)$, que passa de 9,2 milhões de pessoas, em 2003, para 8,8 milhões, em 2004. Trata-se de uma forma de ocupação anacrônica, geralmente no âmbito de uma atividade familiar, que encobre o desemprego de alguns membros secundários da família. Esses fatores tomados em conjunto contribuíram para o aumento da renda das famílias na base da distribuição e conseqüente redução da pobreza e da indigência.

\section{2_ Redução da desigualdade de rendimentos}

O rendimento médio do trabalho ficou constante, mas ocorreram mudanças distributivas, a saber, aumento dos rendimentos mais baixos e redução dos mais altos o que contribuiu tanto para reduzir a pobreza/indigência como a desigualdade de rendimentos. Cabe destacar que, com a saída do mercado de indivíduos de baixa qualificação (menos de oito anos de escolaridade), substituídos por aqueles mais qualificados, mas remunerados com rendimentos mais baixos por ano de estudo, verifica-se declínio do retorno à educação, reconhecidamente muito elevado no Brasil. Cabe acompanhar como a escolaridade crescente e o comportamento do PIB vão repercutir sobre os níveis de pobreza e desigualdade de renda daqui para a frente.

\subsection{O comportamento favorável do preço dos alimentos}

Embora se verifique no Brasil uma tendência robusta de queda dos preços alimentares no longo prazo, a evolução particularmente favorável ocorrida em 2004 certamente contribuiu para reduzir pobreza e indigência. O INPC alimentação ficou em 4\%, bem abaixo do INPC geral (6\%). Cabe notar que a deflação do preço dos alimentos em Salvador, assim como a virtual estabilidade em Recife, teve impactos favoráveis sobre os indicadores de indigência, 
mas também afetou os indicadores de pobreza em razão da participação relativamente elevada dos gastos alimentares no conjunto das despesas dos pobres.

\section{4_ A expansão forte dos benefícios assistenciais}

O número de benefícios mensais de prestação continuada concedidos no âmbito da Lei Orgânica da Assistência Social a idosos e a portadores de deficiência apresentou aumento forte, passando de 1,7 milhão para 2,0 milhões $(+19,5 \%)$. O valor mensal pago no mês de referência da PNAD aumentou de $\mathrm{R} \$ 401,6$ milhões, em setembro de 2003, para R \$ 518,5 milhões, em setembro de 2004 , ou seja, um acréscimo de $22 \%$ em valores constantes. Essa evolução está associada, portanto, tanto a uma expansão forte de cobertura como ao ganho real do valor do salário mínimo, que define o valor desses benefícios.

\section{5_A política de valorização do salário mínimo}

O ganho real do salário mínimo - 2,25\% acima do INPC - contribuiu para que o rendimento médio real para os ocupados com rendimentos entre um e dois salários mínimos apresentasse ganho real de 4,2\% (passando de R\$374,80 para R\$390,40). Tal evolução é especialmente relevante porque trabalhadores nessa faixa de rendimento se constituem um contingente ex- pressivo, isto é, 24 milhões de trabalhadores ou $27,6 \%$ do total de ocupados. Embora aparentemente pequeno, o aumento real do salário mínimo teve também efeito favorável sobre a renda familiar via os proventos de aposentadoria e pensões, assim como via benefícios de prestação continuada, cujo valor é igual a um salário mínimo.

\section{6_ 0 aumento da cobertura e do valor dos benefícios dos novos programas de transferência de renda}

Informações diversas, em especial de fontes oficiais, dão conta de um aumento de cobertura dos programas de transferência de renda com condicionalidades, que vem sendo integrados paulatinamente no Bolsa-Família. Certamente essas transferências, mesmo com eventuais problemas de focalização, contribuíram para a redução da pobreza e da indigência. Infelizmente os dados básicos da PNAD agora divulgados não permitem medir de forma rigorosa o impacto desses benefícios. ${ }^{17} \mathrm{No}$ entanto, houve forte aumento de "outros rendimentos" na formação da renda das famílias que constituem a população-alvo desses benefícios, isto é, famílias com renda familiar per capita inferior a $\mathrm{R} \$ 100,00$ : a participação passou de $5,6 \%$ para $10 \%$, o que contribuiu tanto para reduzir a proporção de pobres como também para elevar o nível de renda daqueles que permaneceram abaixo da linha de pobreza. $\cdots \cdots \cdots \cdots$

17 As informações quanto à participação da família nos diferentes programas, investigadas como quesitos suplementares da PNAD, permitirão alguma avaliação quando o suprimento da pesquisa for divulgado em março de 2006. 


\section{Referências bibliográficas}

BARROS, R. P., CARVALHO, M., FRANCO, S. Is the recent steady and sharp decline in income inequality in Brazil a sustainable process? Rio de Janeiro: IPEA, 2006.

BRASIL. Ministério da

Previdência e da Assistência Social. Disponível em:

$<$ http://www.mpas.gov.br_Hlt14 1345806/_Hlt141345806>.

HOFFMANN, R. Transferências de renda e redução da desigualdade e da pobreza no Brasil. Brasília: CGEE/IPEA/IBGE, 2006.

HOFFMANN, R., KAGEYAMA, A. A trajetória da pobreza no Brasil 1992-2004. Campinas: Instituto de Economia, 2006.

IBGE. Pesquisa Nacional por Amostra de Domicílios, microdados, diversos anos.

NÉRI, M. C. Miséria em queda. Mensuração, monitoramento e metas. Rio de Janeiro: FGV, 2005. ROCHA, S. Do consumo observado à linha de pobreza. Pesquisa e Planejamento Econômico, v. 27, n. 2, p. 313-352, ago. 1997.

ROCHA, S. Pobreza no Brasil. Afinal de que se trata? Rio de Janeiro, FGV, 2005.
SOARES, S. S. D. Distribuicão de renda no Brasil de 1976 a 2004 com ênfase no período entre 2001 e 2004. Rio de Janeiro: IPEA, fev. 2006. (Texto para Discussão n. 1.166).

\footnotetext{
- A autora agradece aos

- pareceristas anônimos, cujos

- comentários e recomendações

- permitiram melhorar em muito

- o texto original.

Artigo recebido em março de 2006

. e aprovado em maio de 2006.

-

- E-mail de contato do autor:

sonrocha@terra.com.br ......... .
} 


\section{A_Estabelecimento das linhas de pobreza e indigência}

Para a derivação de indicadores de insuficiência de renda, foram utilizadas 23 linhas de pobreza e 23 linhas de indigência diferenciadas, estabelecidas segundo o procedimento proposto por Rocha (1997). Tais linhas apresentam duas características básicas.

Elas não são, em primeiro lugar, parâmetros normativos, isto é, não estão associadas a uma estrutura de consumopadrão ou otimizada. Refletem, na verdade, a composição do consumo das populações de baixa renda, efetivamente verificada em pesquisa de orçamentos familiares (IBGE-POF, 1987). A cesta de produtos alimentares considerada, por exemplo, resulta dos hábitos e preferências das famílias pobres, submetidos à restrição de renda, sendo ajustada, apenas marginalmente, nas quantidades de seus produtos, de modo a atender aos requisitos nutricionais médios da população da região ou situação de domicílio considerada.
A segunda característica é que os parâmetros incorporam as significativas diferenças de padrões de consumo e preços pagos pelos consumidores entre as regiões do País e as áreas metropolitana, urbana não-metropolitana e rural em cada uma delas. O ponto de partida são os parâmetros derivados da POF para cada uma das nove Regiões Metropolitanas (Belém, Fortaleza, Recife, Salvador, Belo Horizonte, Rio de Janeiro, São Paulo, Curitiba e Porto Alegre), além de Brasília (Distrito Federal), com base nos quais se obtêm os valores das linhas para as áreas urbanas e rurais de cada região tendo em vista os coeficientes constantes de custo verificados por Fava (1984). Os valores obtidos para o ano-base são atualizados anualmente com base na evolução do INPC/IBGE por grupos de produtos e segundo regiões metropolitanas.

O conjunto de linhas de pobreza e de indigência relativas a 2004 são apresentadas na tabela abaixo. 
(Valores em R\$ “per capita"/por mês) setembro de 2004

\begin{tabular}{|c|c|c|c|c|c|}
\hline \multirow{2}{*}{ Regiões e Estratos } & \multicolumn{2}{|c|}{ Linha } & \multirow{2}{*}{ Regiões e Estratos } & \multicolumn{2}{|c|}{ Linha } \\
\hline & Indigência & Pobreza & & Indigência & Pobreza \\
\hline \multicolumn{3}{|l|}{ Norte } & \multicolumn{3}{|l|}{ São Paulo } \\
\hline Belém & 47,03 & 142,86 & Metrópole & 66,64 & 250,79 \\
\hline Urbano & 46,29 & 124,53 & Urbano & 54,39 & 160,25 \\
\hline Rural & 30,81 & 62,47 & Rural & 42,77 & 100,82 \\
\hline \multicolumn{3}{|l|}{ Nordeste } & \multicolumn{3}{|l|}{ Sul } \\
\hline Fortaleza & 48,84 & 140,35 & Curitiba & 47,83 & 168,54 \\
\hline Recife & 60,92 & 199,81 & Porto Alegre & 51,72 & 132,28 \\
\hline Salvador & 58,15 & 181,19 & Urbano & 45,04 & 112,96 \\
\hline Urbano & 42,21 & 122,62 & Rural & 35,52 & 76,15 \\
\hline Rural & 36,67 & 73,96 & \multicolumn{3}{|l|}{ Centro-Oeste } \\
\hline \multicolumn{3}{|c|}{ Minas Gerais/Espírito Santo } & Brasília & 54,62 & 240,15 \\
\hline Belo Horizonte & 51,79 & 175,24 & Goiânia & 53,52 & 222,86 \\
\hline Urbano & 44,64 & 117,82 & Urbano & 46,57 & 169,69 \\
\hline Rural & 35,81 & 69,75 & Rural & 35,06 & 97,46 \\
\hline \multicolumn{3}{|l|}{ Rio de Janeiro } & & & \\
\hline Metrópole & 67,53 & 209,78 & & & \\
\hline Urbano & 49,02 & 130,52 & & & \\
\hline Rural & 38,71 & 95,28 & & & \\
\hline
\end{tabular}

Fonte: Elaboração própria a partir de microdados da PNAD. 
Aneко B_ Indicadores de indigência 2003-2004

Unidades da Federação e estratos urbano, rural e metropolitano

(continua)

\begin{tabular}{|c|c|c|c|c|c|c|c|c|}
\hline \multirow{2}{*}{ Região/Estado } & \multicolumn{2}{|c|}{ Número de indigentes } & \multicolumn{2}{|c|}{$\begin{array}{c}\text { Proporção } \\
\text { de indigentes (\%) }\end{array}$} & \multicolumn{2}{|c|}{ Hiato de renda } & \multicolumn{2}{|c|}{ Hiato quadrático } \\
\hline & 2003 & 2004 & 2003 & 2004 & 2003 & 2004 & 2003 & 2004 \\
\hline
\end{tabular}

\begin{tabular}{|c|c|c|c|c|c|c|c|c|}
\hline \multicolumn{9}{|l|}{ Norte } \\
\hline Rondônia & 58.177 & 44.443 & 6,0 & 4,4 & 0,615 & 0,612 & 0,031 & 0,023 \\
\hline Urbano & 58.177 & 44.443 & 6,0 & 4,4 & 0,615 & 0,612 & 0,031 & 0,023 \\
\hline Acre & 51.884 & 41.349 & 12,8 & 9,7 & 0,515 & 0,521 & 0,047 & 0,038 \\
\hline Urbano & 51.884 & 41.349 & 12,8 & 9,7 & 0,515 & 0,521 & 0,047 & 0,038 \\
\hline Amazonas & 294.032 & 242.394 & 12,6 & 9,9 & 0,595 & 0,672 & 0,064 & 0,059 \\
\hline Urbano & 294.032 & 242.394 & 12,6 & 9,9 & 0,595 & 0,672 & 0,064 & 0,059 \\
\hline Roraima & 28.005 & 49.398 & 9,9 & 16,5 & 0,588 & 0,574 & 0,043 & 0,073 \\
\hline Urbano & 28.005 & 49.398 & 9,9 & 16,5 & 0,588 & 0,574 & 0,043 & 0,073 \\
\hline Pará & 496.209 & 432.042 & 11,0 & 8,8 & 0,555 & 0,551 & 0,049 & 0,039 \\
\hline Belém & 206.876 & 173.784 & 11,7 & 9,0 & 0,662 & 0,606 & 0,065 & 0,045 \\
\hline Urbano & 289.333 & 258.258 & 10,6 & 8,7 & 0,478 & 0,513 & 0,039 & 0,035 \\
\hline Amapá & 64.224 & 51.913 & 13,2 & 10,1 & 0,578 & 0,501 & 0,062 & 0,038 \\
\hline Urbano & 64.224 & 51.913 & 13,2 & 10,1 & 0,578 & 0,501 & 0,062 & 0,038 \\
\hline Tocantins & 79.916 & 57.638 & 9,1 & 6,4 & 0,575 & 0,523 & 0,043 & 0,025 \\
\hline Urbano & 79.916 & 57.638 & 9,1 & 6,4 & 0,575 & 0,523 & 0,043 & 0,025 \\
\hline NORTE & 1.072 .447 & 919.177 & 10,9 & 8,7 & 0,571 & 0,581 & 0,051 & 0,042 \\
\hline Metropolitano & 206.876 & 173.784 & 11,7 & 9,0 & 0,662 & 0,606 & 0,065 & 0,045 \\
\hline Urbano & 865.571 & 745.393 & 10,7 & 8,7 & 0,549 & 0,575 & 0,048 & 0,041 \\
\hline \multicolumn{9}{|l|}{ Nordeste } \\
\hline Maranhão & 1.174 .870 & 1.197.118 & 20,1 & 20,6 & 0,480 & 0,516 & 0,066 & 0,077 \\
\hline Urbano & 660.974 & 650.366 & 16,7 & 16,2 & 0,468 & 0,543 & 0,056 & 0,066 \\
\hline Rural & 513.896 & 546.752 & 27,2 & 30,2 & 0,495 & 0,483 & 0,088 & 0,102 \\
\hline
\end{tabular}


Anexo B_ Indicadores de indigência 2003-2004

Unidades da Federação e estratos urbano, rural e metropolitano

(continua)

\begin{tabular}{|c|c|c|c|c|c|c|c|c|}
\hline \multirow[t]{2}{*}{ Região/Estado } & \multicolumn{2}{|c|}{ Número de indigentes } & \multicolumn{2}{|c|}{$\begin{array}{c}\text { Proporção } \\
\text { de indigentes (\%) }\end{array}$} & \multicolumn{2}{|c|}{ Hiato de renda } & \multicolumn{2}{|c|}{ Hiato quadrático } \\
\hline & 2003 & 2004 & 2003 & 2004 & 2003 & 2004 & 2003 & 2004 \\
\hline Piauí & 709.785 & 472.297 & 24,6 & 16,0 & 0,475 & 0,482 & 0,077 & 0,052 \\
\hline Urbano & 326.378 & 205.841 & 18,2 & 11,2 & 0,496 & 0,497 & 0,064 & 0,039 \\
\hline Rural & 383.407 & 266.456 & 35,2 & 23,8 & 0,458 & 0,471 & 0,098 & 0,075 \\
\hline Ceará & 1.369 .297 & 1.144 .363 & 17,8 & 14,6 & 0,487 & 0,461 & 0,060 & 0,045 \\
\hline Fortaleza & 390.906 & 349.027 & 12,4 & 10,8 & 0,559 & 0,582 & 0,056 & 0,050 \\
\hline Urbano & 491.643 & 445.822 & 17,8 & 15,6 & 0,468 & 0,423 & 0,057 & 0,041 \\
\hline Rural & 486.748 & 349.514 & 27,5 & 19,8 & 0,448 & 0,389 & 0,074 & 0,043 \\
\hline Rio Grande do Norte & 427.328 & 364.194 & 14,8 & 12,3 & 0,484 & 0,571 & 0,050 & 0,055 \\
\hline Urbano & 265.320 & 248.568 & 12,7 & 11,3 & 0,511 & 0,615 & 0,047 & 0,056 \\
\hline Rural & 162.008 & 115.626 & 20,3 & 15,0 & 0,440 & 0,477 & 0,059 & 0,051 \\
\hline Paraíba & 535.202 & 440.296 & 15,3 & 12,4 & 0,467 & 0,509 & 0,050 & 0,046 \\
\hline Urbano & 342.858 & 309.204 & 12,8 & 11,5 & 0,492 & 0,536 & 0,047 & 0,047 \\
\hline Rural & 192.344 & 131.092 & 23,3 & 15,3 & 0,422 & 0,447 & 0,060 & 0,042 \\
\hline Pernambuco & 1.715 .882 & 1.372 .051 & 21,7 & 16,8 & 0,499 & 0,508 & 0,080 & 0,063 \\
\hline Recife & 747.858 & 609.465 & 22,7 & 17,6 & 0,532 & 0,519 & 0,096 & 0,068 \\
\hline Urbano & 477.126 & 342.452 & 17,6 & 12,2 & 0,497 & 0,525 & 0,064 & 0,049 \\
\hline Rural & 490.898 & 420.134 & 25,8 & 22,2 & 0,450 & 0,479 & 0,075 & 0,074 \\
\hline Alagoas & 575.532 & 529.780 & 19,8 & 18,0 & 0,437 & 0,515 & 0,057 & 0,068 \\
\hline Urbano & 318.217 & 278.974 & 16,3 & 14,4 & 0,443 & 0,596 & 0,050 & 0,068 \\
\hline Rural & 257.315 & 250.806 & 26,6 & 24,9 & 0,429 & 0,425 & 0,069 & 0,066 \\
\hline Sergipe & 271.440 & 150.905 & 14,6 & 7,9 & 0,473 & 0,451 & 0,048 & 0,024 \\
\hline Urbano & 217.344 & 116.441 & 14,4 & 7,4 & 0,488 & 0,476 & 0,051 & 0,025 \\
\hline Rural & 54.096 & 34.464 & 15,6 & 10,3 & 0,415 & 0,365 & 0,037 & 0,021 \\
\hline
\end{tabular}


Anexо B_ Indicadores de indigência 2003-2004

Unidades da Federação e estratos urbano, rural e metropolitano

(continua)

\begin{tabular}{|c|c|c|c|c|c|c|c|c|}
\hline \multirow[t]{2}{*}{ Região/Estado } & \multicolumn{2}{|c|}{ Número de indigentes } & \multicolumn{2}{|c|}{$\begin{array}{c}\text { Proporção } \\
\text { de indigentes (\%) }\end{array}$} & \multicolumn{2}{|c|}{ Hiato de renda } & \multicolumn{2}{|c|}{ Hiato quadrático } \\
\hline & 2003 & 2004 & 2003 & 2004 & 2003 & 2004 & 2003 & 2004 \\
\hline Bahia & 2.299 .494 & 1.721 .580 & 17,5 & 12,9 & 0,482 & 0,510 & 0,061 & 0,049 \\
\hline Salvador & 553.279 & 447.030 & 17,8 & 14,2 & 0,583 & 0,557 & 0,082 & 0,061 \\
\hline Urbano & 897.307 & 644.184 & 15,7 & 10,9 & 0,468 & 0,525 & 0,053 & 0,043 \\
\hline Rural & 848.908 & 630.366 & 19,7 & 14,7 & 0,431 & 0,461 & 0,056 & 0,048 \\
\hline NORDESTE & 9.078 .830 & 7.392 .584 & 18,7 & 14,9 & 0,481 & 0,503 & 0,063 & 0,054 \\
\hline Metropolitano & 1.692 .043 & 1.405 .522 & 17,7 & 14,3 & 0,555 & 0,547 & 0,078 & 0,060 \\
\hline Urbano & 3.997 .167 & 3.241 .852 & 15,9 & 12,6 & 0,478 & 0,525 & 0,054 & 0,049 \\
\hline Rural & 3.389 .620 & 2.745 .210 & 24,4 & 19,8 & 0,448 & 0,455 & 0,070 & 0,060 \\
\hline
\end{tabular}

\begin{tabular}{|c|c|c|c|c|c|c|c|c|}
\hline \multicolumn{9}{|l|}{ Sudeste } \\
\hline Minas Gerais & 1.299 .905 & 958.631 & 7,1 & 5,1 & 0,560 & 0,599 & 0,032 & 0,025 \\
\hline Belo Horizonte & 254.872 & 240.441 & 5,7 & 5,2 & 0,606 & 0,608 & 0,029 & 0,027 \\
\hline Urbano & 744.901 & 570.618 & 6,8 & 5,1 & 0,571 & 0,596 & 0,032 & 0,024 \\
\hline Rural & 300.132 & 147.572 & 11,0 & 5,3 & 0,496 & 0,593 & 0,040 & 0,025 \\
\hline Espírito Santo & 200.340 & 167.275 & 6,3 & 5,1 & 0,636 & 0,670 & 0,033 & 0,029 \\
\hline Urbano & 142.634 & 129.690 & 5,5 & 4,8 & 0,713 & 0,696 & 0,034 & 0,029 \\
\hline Rural & 57.706 & 37.585 & 9,8 & 6,5 & 0,447 & 0,581 & 0,030 & 0,029 \\
\hline Rio de Janeiro & 940.203 & 892.397 & 6,6 & 6,3 & 0,561 & 0,558 & 0,030 & 0,029 \\
\hline Metrópole & 784.348 & 737.453 & 7,4 & 7,0 & 0,533 & 0,537 & 0,031 & 0,031 \\
\hline Urbano & 145.471 & 139.715 & 4,5 & 4,2 & 0,683 & 0,684 & 0,027 & 0,026 \\
\hline Rural & 10.384 & 15.229 & 2,5 & 3,8 & 0,936 & 0,452 & 0,023 & 0,014 \\
\hline São Paulo & 2.462 .593 & 2.030 .050 & 6,5 & 5,3 & 0,608 & 0,618 & 0,034 & 0,028 \\
\hline Metrópole & 1.634 .349 & 1.308 .273 & 9,2 & 7,2 & 0,610 & 0,632 & 0,047 & 0,039 \\
\hline Urbano & 774.506 & 653.201 & 4,2 & 3,4 & 0,597 & 0,588 & 0,022 & 0,017 \\
\hline Rural & 53.738 & 68.576 & 3,8 & 4,7 & 0,679 & 0,616 & 0,023 & 0,025 \\
\hline
\end{tabular}


Anexo B_ Indicadores de indigência 2003-2004

Unidades da Federação e estratos urbano, rural e metropolitano

(continua)

\begin{tabular}{|c|c|c|c|c|c|c|c|c|}
\hline \multirow[t]{2}{*}{ Região/Estado } & \multicolumn{2}{|c|}{ Número de indigentes } & \multicolumn{2}{|c|}{$\begin{array}{c}\text { Proporção } \\
\text { de indigentes (\%) }\end{array}$} & \multicolumn{2}{|c|}{ Hiato de renda } & \multicolumn{2}{|c|}{ Hiato quadrático } \\
\hline & 2003 & 2004 & 2003 & 2004 & 2003 & 2004 & 2003 & 2004 \\
\hline SUDESTE & 4.903 .041 & 4.048 .353 & 6,7 & 5,4 & 0,587 & 0,602 & 0,033 & 0,027 \\
\hline Metropolitano & 2.673 .569 & 2.286 .167 & 8,1 & 6,9 & 0,587 & 0,599 & 0,040 & 0,035 \\
\hline Urbano & 1.807 .512 & 1.493 .224 & 5,1 & 4,1 & 0,602 & 0,610 & 0,026 & 0,021 \\
\hline Rural & 421.960 & 268.962 & 8,2 & 5,1 & 0,523 & 0,589 & 0,033 & 0,025 \\
\hline
\end{tabular}

\begin{tabular}{|c|c|c|c|c|c|c|c|c|}
\hline \multicolumn{9}{|l|}{ Sul } \\
\hline Paraná & 421.984 & 368.065 & 4,3 & 3,7 & 0,600 & 0,603 & 0,022 & 0,018 \\
\hline Curitiba & 128.811 & 84.752 & 4,4 & 2,8 & 0,677 & 0,686 & 0,027 & 0,017 \\
\hline Urbano & 221.677 & 197.839 & 4,0 & 3,5 & 0,588 & 0,583 & 0,020 & 0,016 \\
\hline Rural & 71.496 & 85.474 & 5,4 & 6,2 & 0,502 & 0,566 & 0,020 & 0,027 \\
\hline Santa Catarina & 157.509 & 110.056 & 2,9 & 1,9 & 0,732 & 0,650 & 0,019 & 0,011 \\
\hline Urbano & 136.627 & 75.294 & 3,0 & 1,6 & 0,729 & 0,729 & 0,021 & 0,011 \\
\hline Rural & 20.882 & 34.762 & 2,1 & 3,4 & 0,747 & 0,479 & 0,014 & 0,012 \\
\hline Rio Grande do Sul & 479.977 & 442.753 & 4,6 & 4,2 & 0,588 & 0,570 & 0,022 & 0,020 \\
\hline Porto Alegre & 176.067 & 161.590 & 4,6 & 4,2 & 0,612 & 0,580 & 0,023 & 0,021 \\
\hline Urbano & 219.392 & 168.236 & 4,6 & 3,5 & 0,590 & 0,585 & 0,023 & 0,016 \\
\hline Rural & 84.518 & 112.927 & 4,7 & 6,2 & 0,532 & 0,533 & 0,020 & 0,025 \\
\hline SUL & 1.059 .470 & 920.874 & 4,1 & 3,5 & 0,614 & 0,593 & 0,022 & 0,017 \\
\hline Metropolitano & 304.878 & 246.342 & 4,5 & 3,6 & 0,640 & 0,617 & 0,025 & 0,019 \\
\hline Urbano & 577.696 & 441.369 & 3,9 & 2,9 & 0,622 & 0,609 & 0,021 & 0,015 \\
\hline Rural & 176.896 & 233.163 & 4,3 & 5,5 & 0,545 & 0,537 & 0,019 & 0,023 \\
\hline
\end{tabular}

Centro-Oeste

\begin{tabular}{|c|c|c|c|c|c|c|c|c|}
\hline Mato Grosso do Sul & 110.227 & 120.289 & 5,1 & 5,4 & 0,625 & 0,618 & 0,027 & 0,028 \\
\hline Urbano & 85.877 & 92.234 & 4,7 & 4,9 & 0,609 & 0,630 & 0,024 & 0,026 \\
\hline
\end{tabular}


Anexо B_ Indicadores de indigência 2003-2004

Unidades da Federação e estratos urbano, rural e metropolitano

\begin{tabular}{|c|c|c|c|c|c|c|c|c|}
\hline Região/Estado & \multicolumn{2}{|c|}{ Número de indigentes } & \multicolumn{2}{|c|}{$\begin{array}{c}\text { Proporção } \\
\text { de indigentes }(\%)\end{array}$} & \multicolumn{2}{|c|}{ Hiato de renda } & \multicolumn{2}{|c|}{ Hiato quadrático } \\
\hline Mato Grosso & 151.698 & 108.226 & 5,9 & 4,0 & 0,680 & 0,673 & 0,035 & 0,024 \\
\hline Urbano & 103.628 & 73.579 & 5,2 & 3,5 & 0,711 & 0,680 & 0,034 & 0,021 \\
\hline Rural & 48.070 & 34.647 & 8,1 & 5,5 & 0,612 & 0,657 & 0,042 & 0,034 \\
\hline Goiás & 326.508 & 202.795 & 6,2 & 3,7 & 0,644 & 0,662 & 0,034 & 0,022 \\
\hline Urbano & 273.928 & 181.756 & 5,9 & 3,8 & 0,659 & 0,670 & 0,034 & 0,022 \\
\hline Rural & 52.580 & 21.039 & 8,1 & 3,1 & 0,567 & 0,588 & 0,037 & 0,015 \\
\hline Distrito Federal & 188.033 & 182.684 & 8,8 & 8,2 & 0,579 & 0,645 & 0,044 & 0,046 \\
\hline Distrito Federal & 188.033 & 182.684 & 8,8 & 8,2 & 0,579 & 0,645 & 0,044 & 0,046 \\
\hline Urbano & 463.433 & 347.569 & 5,5 & 3,9 & 0,661 & 0,662 & 0,032 & 0,023 \\
\hline Rural & 125.000 & 83.741 & 8,0 & 5,1 & 0,607 & 0,613 & 0,040 & 0,027 \\
\hline
\end{tabular}

\begin{tabular}{|c|c|c|c|c|c|c|c|c|}
\hline \multicolumn{9}{|l|}{ Brasil } \\
\hline Norte & 1.072 .447 & 919.177 & 10,9 & 8,7 & 0,571 & 0,581 & 0,051 & 0,042 \\
\hline Nordeste & 9.078 .830 & 7.392 .584 & 18,7 & 14,9 & 0,481 & 0,503 & 0,063 & 0,054 \\
\hline Sudeste & 4.903 .041 & 4.048 .353 & 6,7 & 5,4 & 0,587 & 0,602 & 0,033 & 0,027 \\
\hline Sul & 1.059 .470 & 920.874 & 4,1 & 3,5 & 0,614 & 0,593 & 0,022 & 0,017 \\
\hline Centro-Oeste & 776.466 & 613.994 & 6,4 & 4,8 & 0,633 & 0,650 & 0,035 & 0,027 \\
\hline BRASIL & 16.890 .254 & 13.894 .982 & 10,0 & 8,0 & 0,533 & 0,550 & 0,041 & 0,034 \\
\hline Metropolitano & 5.065 .399 & 4.294.499 & 9,5 & 7,9 & 0,582 & 0,585 & 0,046 & 0,038 \\
\hline Urbano & 7.711 .379 & 6.269 .407 & 8,4 & 6,6 & 0,537 & 0,565 & 0,035 & 0,030 \\
\hline Rural & 4.113 .476 & 3.331 .076 & 16,6 & 13,3 & 0,465 & 0,476 & 0,051 & 0,044 \\
\hline
\end{tabular}

Fonte: IBGE/PNAD, 2003 e 2004 - Tabulações Especiais. 
Anexo C_ Indicadores de pobreza - 2003 e 2004

Unidades da Federação e estratos urbano, rural e metropolitano

(continua)

\begin{tabular}{|c|c|c|c|c|c|c|c|c|}
\hline \multirow[t]{2}{*}{ Região/Estado } & \multicolumn{2}{|c|}{ Número de pobres } & \multicolumn{2}{|c|}{$\begin{array}{c}\text { Proporção } \\
\text { de Pobres (\%) }\end{array}$} & \multicolumn{2}{|c|}{ Hiato de renda } & \multicolumn{2}{|c|}{ Hiato quadrático } \\
\hline & 2003 & 2004 & 2003 & 2004 & 2003 & 2004 & 2003 & 2004 \\
\hline \multicolumn{9}{|l|}{ Norte } \\
\hline Rondônia & 286.426 & 230.965 & 29,7 & 22,9 & 0,404 & 0,376 & 0,072 & 0,051 \\
\hline Urbano & 286.426 & 230.965 & 29,7 & 22,9 & 0,404 & 0,376 & 0,072 & 0,051 \\
\hline Acre & 165.883 & 167.892 & 40,8 & 39,5 & 0,480 & 0,461 & 0,128 & 0,111 \\
\hline Urbano & 165.883 & 167.892 & 40,8 & 39,5 & 0,480 & 0,461 & 0,128 & 0,111 \\
\hline Amazonas & 992.222 & 863.232 & 42,7 & 35,4 & 0,485 & 0,483 & 0,137 & 0,113 \\
\hline Urbano & 992.222 & 863.232 & 42,7 & 35,4 & 0,485 & 0,483 & 0,137 & 0,113 \\
\hline Roraima & 105.661 & 137.263 & 37,5 & 45,7 & 0,461 & 0,536 & 0,108 & 0,166 \\
\hline Urbano & 105.661 & 137.263 & 37,5 & 45,7 & 0,461 & 0,536 & 0,108 & 0,166 \\
\hline Pará & 2.067 .870 & 1.971 .148 & 45,9 & 40,0 & 0,453 & 0,429 & 0,129 & 0,104 \\
\hline Belém & 802.886 & 782.876 & 45,4 & 40,3 & 0,472 & 0,442 & 0,143 & 0,112 \\
\hline Urbano & 1.264 .984 & 1.188 .272 & 46,3 & 39,8 & 0,442 & 0,420 & 0,121 & 0,098 \\
\hline Amapá & 194.585 & 211.584 & 39,9 & 41,3 & 0,518 & 0,453 & 0,138 & 0,113 \\
\hline Urbano & 194.585 & 211.584 & 39,9 & 41,3 & 0,518 & 0,453 & 0,138 & 0,113 \\
\hline Tocantins & 335.154 & 273.343 & 38,0 & 30,5 & 0,438 & 0,420 & 0,102 & 0,075 \\
\hline Urbano & 335.154 & 273.343 & 38,0 & 30,5 & 0,438 & 0,420 & 0,102 & 0,075 \\
\hline NORTE & 4.147.801 & 3.855 .427 & 42,1 & 36,7 & 0,461 & 0,444 & 0,123 & 0,101 \\
\hline Metropolitano & 802.886 & 782.876 & 45,4 & 40,3 & 0,472 & 0,442 & 0,143 & 0,112 \\
\hline Urbano & 3.344 .915 & 3.072 .551 & 41,4 & 35,9 & 0,458 & 0,444 & 0,119 & 0,098 \\
\hline \multicolumn{9}{|l|}{ Nordeste } \\
\hline Maranhão & 3.163 .394 & 3.112 .352 & 54,2 & 53,5 & 0,500 & 0,512 & 0,174 & 0,182 \\
\hline Urbano & 2.133 .969 & 2.018 .045 & 54,0 & 50,4 & 0,497 & 0,513 & 0,171 & 0,173 \\
\hline Rural & 1.029 .425 & 1.094 .307 & 54,6 & 60,5 & 0,504 & 0,510 & 0,181 & 0,203 \\
\hline
\end{tabular}


Anexo C_ Indicadores de pobreza - 2003 e 2004

Unidades da Federação e estratos urbano, rural e metropolitano

\begin{tabular}{|c|c|c|c|c|c|c|c|c|}
\hline Região/Estado & \multicolumn{2}{|c|}{ Número de pobres } & \multicolumn{2}{|c|}{$\begin{array}{c}\text { Proporção } \\
\text { de Pobres (\%) }\end{array}$} & \multicolumn{2}{|c|}{ Hiato de renda } & \multicolumn{2}{|c|}{ Hiato quadrático } \\
\hline Piauí & 1.485 .770 & 1.396 .507 & 51,6 & 47,3 & 0,533 & 0,469 & 0,185 & 0,139 \\
\hline Urbano & 832.503 & 826.510 & 46,5 & 45,0 & 0,529 & 0,451 & 0,168 & 0,125 \\
\hline Rural & 653.267 & 569.997 & 59,9 & 50,9 & 0,538 & 0,496 & 0,213 & 0,163 \\
\hline Ceará & 3.965 .618 & 4.030 .612 & 51,7 & 51,4 & 0,496 & 0,453 & 0,164 & 0,142 \\
\hline Fortaleza & 1.544 .345 & 1.579 .066 & 49,2 & 48,9 & 0,476 & 0,446 & 0,148 & 0,136 \\
\hline Urbano & 1.472 .003 & 1.538 .694 & 53,3 & 54,0 & 0,519 & 0,476 & 0,179 & 0,159 \\
\hline Rural & 949.270 & 912.852 & 53,7 & 51,7 & 0,492 & 0,428 & 0,169 & 0,128 \\
\hline Urbano & 858.403 & 901.112 & 41,0 & 41,1 & 0,487 & 0,487 & 0,129 & 0,131 \\
\hline Rural & 382.716 & 303.323 & 47,9 & 39,2 & 0,443 & 0,462 & 0,131 & 0,111 \\
\hline Paraíba & 1.667 .156 & 1.626 .007 & 47,5 & 45,9 & 0,477 & 0,463 & 0,141 & 0,131 \\
\hline Urbano & 1.261 .793 & 1.248 .091 & 47,1 & 46,5 & 0,478 & 0,475 & 0,140 & 0,138 \\
\hline Rural & 405.363 & 377.916 & 49,1 & 44,0 & 0,475 & 0,423 & 0,144 & 0,109 \\
\hline Pernambuco & 4.551 .287 & 4.377 .283 & 57,6 & 53,7 & 0,521 & 0,504 & 0,201 & 0,176 \\
\hline Recife & 2.084 .421 & 2.072 .678 & 63,3 & 59,9 & 0,547 & 0,537 & 0,240 & 0,215 \\
\hline Urbano & 1.474 .217 & 1.352 .921 & 54,5 & 48,3 & 0,517 & 0,475 & 0,184 & 0,145 \\
\hline Rural & 992.649 & 951.684 & 52,2 & 50,2 & 0,469 & 0,475 & 0,157 & 0,153 \\
\hline Urbano & 1.050 .337 & 981.884 & 54,0 & 50,7 & 0,496 & 0,505 & 0,167 & 0,169 \\
\hline Rural & 569.579 & 537.499 & 58,9 & 53,4 & 0,463 & 0,476 & 0,166 & 0,159 \\
\hline Sergipe & 776.323 & 700.004 & 41,8 & 36,5 & 0,487 & 0,428 & 0,132 & 0,091 \\
\hline Urbano & 624.340 & 585.232 & 41,4 & 37,0 & 0,506 & 0,433 & 0,138 & 0,094 \\
\hline Rural & 151.983 & 114.772 & 43,8 & 34,3 & 0,406 & 0,401 & 0,102 & 0,074 \\
\hline
\end{tabular}


Anexo C_ Indicadores de pobreza - 2003 e 2004

Unidades da Federação e estratos urbano, rural e metropolitano

(continua)

\begin{tabular}{|c|c|c|c|c|c|c|c|c|}
\hline \multirow[t]{2}{*}{ Região/Estado } & \multicolumn{2}{|c|}{ Número de pobres } & \multicolumn{2}{|c|}{$\begin{array}{c}\text { Proporção } \\
\text { de Pobres (\%) }\end{array}$} & \multicolumn{2}{|c|}{ Hiato de renda } & \multicolumn{2}{|c|}{ Hiato quadrático } \\
\hline & 2003 & 2004 & 2003 & 2004 & 2003 & 2004 & 2003 & 2004 \\
\hline Bahia & 6.749 .914 & 6.034 .107 & 51,4 & 45,3 & 0,487 & 0,462 & 0,160 & 0,131 \\
\hline Salvador & 1.758 .497 & 1.629 .662 & 56,6 & 51,7 & 0,529 & 0,498 & 0,203 & 0,170 \\
\hline Urbano & 2.841 .346 & 2.671 .253 & 49,7 & 45,4 & 0,502 & 0,464 & 0,160 & 0,130 \\
\hline Rural & 2.150 .071 & 1.733 .192 & 49,9 & 40,5 & 0,435 & 0,424 & 0,130 & 0,104 \\
\hline NORDESTE & 25.220 .497 & 24.000 .690 & 51,9 & 48,5 & 0,497 & 0,477 & 0,167 & 0,147 \\
\hline Metropolitano & 5.387 .263 & 5.281 .406 & 56,5 & 53,6 & 0,521 & 0,498 & 0,198 & 0,174 \\
\hline Urbano & 12.548 .911 & 12.123 .742 & 49,9 & 47,0 & 0,503 & 0,479 & 0,161 & 0,143 \\
\hline Rural & 7.284 .323 & 6.595 .542 & 52,4 & 47,6 & 0,470 & 0,458 & 0,155 & 0,135 \\
\hline \multicolumn{9}{|l|}{ Sudeste } \\
\hline Minas Gerais & 5.201 .418 & 4.835.389 & 28,5 & 25,9 & 0,438 & 0,408 & 0,077 & 0,063 \\
\hline Belo Horizonte & 1.627 .243 & 1.563 .412 & 36,2 & 34,1 & 0,426 & 0,414 & 0,092 & 0,084 \\
\hline Urbano & 2.793 .235 & 2.624 .432 & 25,3 & 23,3 & 0,449 & 0,421 & 0,072 & 0,058 \\
\hline Rural & 780.940 & 647.545 & 28,7 & 23,1 & 0,422 & 0,343 & 0,076 & 0,046 \\
\hline Espírito Santo & 788.692 & 734.424 & 24,9 & 22,2 & 0,420 & 0,393 & 0,065 & 0,054 \\
\hline Urbano & 629.642 & 593.471 & 24,4 & 21,8 & 0,426 & 0,401 & 0,066 & 0,054 \\
\hline Rural & 159.050 & 140.953 & 27,0 & 24,2 & 0,395 & 0,358 & 0,063 & 0,052 \\
\hline Rio de Janeiro & 4.510 .673 & 4.288 .387 & 31,6 & 30,0 & 0,429 & 0,426 & 0,083 & 0,079 \\
\hline Metrópole & 3.666 .363 & 3.557 .604 & 34,5 & 33,6 & 0,441 & 0,434 & 0,093 & 0,089 \\
\hline Urbano & 742.681 & 643.010 & 23,1 & 19,6 & 0,381 & 0,395 & 0,055 & 0,050 \\
\hline Rural & 101.629 & 87.773 & 24,5 & 22,1 & 0,313 & 0,332 & 0,041 & 0,038 \\
\hline São Paulo & 11.753 .466 & 11.771 .993 & 31,2 & 30,6 & 0,452 & 0,423 & 0,090 & 0,079 \\
\hline Metrópole & 7.291 .532 & 7.505 .622 & 41,0 & 41,6 & 0,491 & 0,452 & 0,132 & 0,118 \\
\hline Urbano & 4.133 .530 & 3.980 .057 & 22,4 & 21,0 & 0,390 & 0,372 & 0,052 & 0,045 \\
\hline Rural & 328.404 & 286.314 & 23,2 & 19,5 & 0,343 & 0,370 & 0,044 & 0,045 \\
\hline
\end{tabular}


Anexo C_ Indicadores de pobreza - 2003 e 2004

Unidades da Federação e estratos urbano, rural e metropolitano

(continua)

\begin{tabular}{|c|c|c|c|c|c|c|c|c|}
\hline \multirow[t]{2}{*}{ Região/Estado } & \multicolumn{2}{|c|}{ Número de pobres } & \multicolumn{2}{|c|}{$\begin{array}{c}\text { Proporção } \\
\text { de Pobres (\%) }\end{array}$} & \multicolumn{2}{|c|}{ Hiato de renda } & \multicolumn{2}{|c|}{ Hiato quadrático } \\
\hline & 2003 & 2004 & 2003 & 2004 & 2003 & 2004 & 2003 & 2004 \\
\hline SUDESTE & 22.254 .249 & 21.630 .193 & 30,4 & 28,9 & 0,443 & 0,419 & 0,084 & 0,074 \\
\hline Metropolitano & 12.585 .138 & 12.626 .638 & 38,2 & 38,0 & 0,468 & 0,442 & 0,114 & 0,104 \\
\hline Urbano & 8.299 .088 & 7.840 .970 & 23,6 & 21,6 & 0,412 & 0,392 & 0,060 & 0,050 \\
\hline Rural & 1.370 .023 & 1.162 .585 & 26,7 & 22,1 & 0,392 & 0,351 & 0,063 & 0,046 \\
\hline
\end{tabular}

\begin{tabular}{|c|c|c|c|c|c|c|c|c|}
\hline \multicolumn{9}{|l|}{ Sul } \\
\hline Paraná & 2.015 .440 & 1.737 .288 & 20,5 & 17,2 & 0,406 & 0,410 & 0,051 & 0,043 \\
\hline Curitiba & 764.594 & 679.908 & 26,2 & 22,4 & 0,429 & 0,405 & 0,069 & 0,053 \\
\hline Urbano & 988.899 & 793.180 & 17,7 & 14,0 & 0,396 & 0,406 & 0,043 & 0,035 \\
\hline Rural & 261.947 & 264.200 & 19,7 & 19,1 & 0,375 & 0,433 & 0,044 & 0,052 \\
\hline Santa Catarina & 500.748 & 511.447 & 9,1 & 9,0 & 0,454 & 0,373 & 0,029 & 0,020 \\
\hline Urbano & 436.959 & 420.503 & 9,7 & 9,0 & 0,461 & 0,357 & 0,031 & 0,019 \\
\hline Rural & 63.789 & 90.944 & 6,4 & 8,8 & 0,408 & 0,445 & 0,019 & 0,025 \\
\hline Rio Grande do Sul & 1.689 .257 & 1.657 .491 & 16,3 & 15,7 & 0,425 & 0,411 & 0,044 & 0,040 \\
\hline Porto Alegre & 677.396 & 635.288 & 17,8 & 16,4 & 0,427 & 0,416 & 0,048 & 0,043 \\
\hline Urbano & 738.059 & 745.696 & 15,5 & 15,4 & 0,435 & 0,387 & 0,044 & 0,036 \\
\hline Rural & 273.802 & 276.507 & 15,1 & 15,2 & 0,391 & 0,461 & 0,037 & 0,046 \\
\hline SUL & 4.205.445 & 3.906 .226 & 16,3 & 14,8 & 0,419 & 0,405 & 0,043 & 0,037 \\
\hline Metropolitano & 1.441 .990 & 1.315 .196 & 21,4 & 19,0 & 0,428 & 0,410 & 0,057 & 0,047 \\
\hline Urbano & 2.163 .917 & 1.959 .379 & 14,6 & 12,9 & 0,422 & 0,389 & 0,040 & 0,030 \\
\hline Rural & 599.538 & 631.651 & 14,5 & 14,9 & 0,386 & 0,447 & 0,035 & 0,043 \\
\hline
\end{tabular}

Centro-Oeste

\begin{tabular}{l|r|r|r|r|r|r|r|l}
\hline Mato Grosso do Sul & 738.977 & 755.719 & 34,1 & 34,0 & 0,424 & 0,411 & 0,086 & 0,083 \\
\hline Urbano & 655.656 & 669.056 & 35,6 & 35,2 & 0,424 & 0,408 & 0,088 & 0,085 \\
\hline Rural & 83.321 & 86.663 & 25,6 & 26,5 & 0,425 & 0,434 & 0,074 & 0,077 \\
\hline
\end{tabular}


Anexo C_ Indicadores de pobreza - 2003 e 2004

Unidades da Federação e estratos urbano, rural e metropolitano

(conclusão)

\begin{tabular}{|c|c|c|c|c|c|c|c|c|}
\hline \multirow[t]{2}{*}{ Região/Estado } & \multicolumn{2}{|c|}{ Número de pobres } & \multicolumn{2}{|c|}{$\begin{array}{c}\text { Proporção } \\
\text { de Pobres (\%) }\end{array}$} & \multicolumn{2}{|c|}{ Hiato de renda } & \multicolumn{2}{|c|}{ Hiato quadrático } \\
\hline & 2003 & 2004 & 2003 & 2004 & 2003 & 2004 & 2003 & 2004 \\
\hline Mato Grosso & 960.710 & 823.920 & 37,3 & 30,1 & 0,424 & 0,396 & 0,096 & 0,069 \\
\hline Urbano & 732.547 & 642.433 & 37,0 & 30,6 & 0,429 & 0,393 & 0,096 & 0,069 \\
\hline Rural & 228.163 & 181.487 & 38,4 & 28,7 & 0,411 & 0,404 & 0,098 & 0,069 \\
\hline Goiás & 1.923 .773 & 1.781 .325 & 36,5 & 32,5 & 0,434 & 0,401 & 0,097 & 0,074 \\
\hline Urbano & 1.717 .113 & 1.602 .679 & 37,1 & 33,3 & 0,437 & 0,410 & 0,099 & 0,078 \\
\hline Rural & 206.660 & 178.646 & 31,7 & 26,7 & 0,411 & 0,328 & 0,081 & 0,045 \\
\hline Distrito Federal & 911.654 & 944.695 & 42,7 & 42,4 & 0,525 & 0,502 & 0,150 & 0,140 \\
\hline Distrito Federal & 911.654 & 944.695 & 42,7 & 42,4 & 0,525 & 0,502 & 0,150 & 0,140 \\
\hline Urbano & 3.105 .316 & 2.914 .168 & 36,8 & 33,1 & 0,432 & 0,406 & 0,096 & 0,077 \\
\hline Rural & 518.144 & 446.796 & 33,0 & 27,5 & 0,413 & 0,379 & 0,086 & 0,061 \\
\hline
\end{tabular}

\begin{tabular}{|c|c|c|c|c|c|c|c|c|}
\hline \multicolumn{9}{|l|}{ Brasil } \\
\hline Norte & 4.147 .801 & 3.855 .427 & 42,1 & 36,7 & 0,461 & 0,444 & 0,123 & 0,101 \\
\hline Nordeste & 25.220 .497 & 24.000 .690 & 51,9 & 48,5 & 0,497 & 0,477 & 0,167 & 0,147 \\
\hline Sudeste & 22.254 .249 & 21.630 .193 & 30,4 & 28,9 & 0,443 & 0,419 & 0,084 & 0,074 \\
\hline Sul & 4.205 .445 & 3.906 .226 & 16,3 & 14,8 & 0,419 & 0,405 & 0,043 & 0,037 \\
\hline BRASIL & 60.363 .106 & 57.698 .195 & 35,6 & 33,2 & 0,466 & 0,444 & 0,105 & 0,092 \\
\hline Metropolitano & 21.128 .931 & 20.950 .811 & 39,8 & 38,7 & 0,482 & 0,457 & 0,124 & 0,111 \\
\hline Urbano & 29.462 .147 & 27.910 .810 & 32,1 & 29,5 & 0,459 & 0,437 & 0,093 & 0,079 \\
\hline Rural & 9.772 .028 & 8.836 .574 & 39,5 & 35,4 & 0,451 & 0,439 & 0,111 & 0,096 \\
\hline
\end{tabular}

Fonte: IBGE/PNAD, 2003 e 2004 - Tabulações Especiais. 